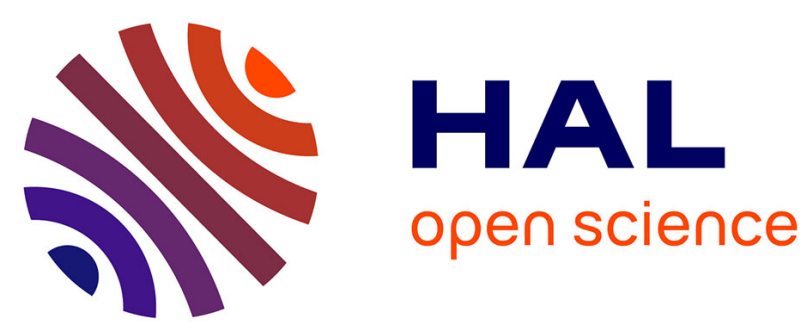

\title{
Source/Goal (a)symmetry
}

\author{
Benjamin Fagard, Anetta Kopecka
}

\section{To cite this version:}

Benjamin Fagard, Anetta Kopecka. Source/Goal (a)symmetry. Studies in Language, 2020, 10.1075/sl.00016.fag . halshs-03087649

\section{HAL Id: halshs-03087649 https://shs.hal.science/halshs-03087649}

Submitted on 24 Dec 2020

HAL is a multi-disciplinary open access archive for the deposit and dissemination of scientific research documents, whether they are published or not. The documents may come from teaching and research institutions in France or abroad, or from public or private research centers.
L'archive ouverte pluridisciplinaire HAL, est destinée au dépôt et à la diffusion de documents scientifiques de niveau recherche, publiés ou non, émanant des établissements d'enseignement et de recherche français ou étrangers, des laboratoires publics ou privés. 


\section{Source/Goal (a)symmetry. A comparative study of German and Polish}

Studies in Language, http://doi.org/10.1075/s1.00016.fag

Benjamin Fagard \& Anetta Kopecka

Laboratoire Lattice (CNRS, ENS \& Sorbonne Nouvelle; PSL) \& Laboratoire Dynamique du Langage, UMR 5596 CNRS \& Université de Lyon

\section{$\underline{\text { Author version }}$}

This paper compares the expression of Source and Goal in German and Polish, on the basis of descriptions elicited with a series of video clips. As satellite-framed languages (Talmy 1985, 2000), both German and Polish mainly rely on grammatical morphemes to encode Path of motion with respect to Source and Goal. Nevertheless, despite this shared typological feature, these languages also display fine morphosyntactic and semantic differences. Our study reveals that the expression of Source and Goal is more asymmetrical in German as compared to Polish, in both the types of linguistic resources and the semantic distinctions. We show that German speakers tend to combine Path satellites with Path verbs - including both deictic satellites and deictic verbs - more frequently in Source-oriented events, depicting them with finer semantic distinctions than Goal-oriented events. In the expression of the Ground, however, they tend to make more distinctions in the expression of Goals as 
compared to Sources, by using a greater variety of prepositions. Polish speakers, by contrast, tend to express Source and Goal in a more symmetrical fashion. These cross-linguistic differences are discussed in the light of language-specific characteristics and their role in the expression - symmetrical or asymmetrical - of Source and Goal.

Keywords: German, Polish, satellite-framed constructions, Path of motion, Source-oriented events, Goal-oriented events, goal-over-source principle, goal bias, Source-Goal asymmetry

\section{$1 \quad$ Introduction $^{1}$}

When describing events, we typically take a perspective - that is, we choose the information we want to convey in discourse and the way to express it. These choices depend on the aspects of the event that attract our attention and on our communicative intentions, as well as on the lexical and grammatical resources provided by our language. This also holds for motion events. For example, when relating the change of location of a Figure (the moving entity) with respect to a Ground (the location with respect to which the Figure moves) from Source (the initial location) via Medial (the intermediate location) to Goal (the final location), we can convey either all three spatial components of Path (e.g. They ran [out of the house]SOURCE [across the field]MEDIAL (and) [into the forest $] \mathrm{GOAL}$ ), or describe one or two of them..$^{2}$ Furthermore, depending on the specificities of the language we speak, we can package such information in one verb clause (as in English), or segment the event into two or three verb clauses, each conveying a different sequence of Path (cf. Bohnemeyer et al. 2007).

\footnotetext{
${ }^{1}$ The study reported in this paper was conducted within the research program TRAJECTOIRE (2008-2011) and supported by the French Federation Typologie et Universaux Linguistiques, CNRS FR2559.

2 Path and Ground are closely related: the Path followed by the Figure is generally defined with respect to the Ground which, depending on the orientation of the Path, can function as Source, Median, or Goal (cf. Talmy 2000).
} 
Interestingly, scholars have observed that speakers of various languages tend to allocate more attention to Goal than to Source (or Medial), and describe endpoints of motion more frequently and in a more fine-grained manner in the linguistic structure by using a greater variety of lexical and grammatical resources (e.g. Ikegami 1987; Bourdin 1997). This preference toward the Goal, also known as goal-over-source principle or goal bias (see e.g. Ungerer \& Schmid 1996; Dirven \& Verspoor 1998; Stefanowitsch and Rohde 2004; Verkerk 2017; Stefanowitsch 2018; Georgakopoulous 2018, inter alia), has often been attributed to its cognitive and pragmatic salience (e.g. Lakusta \& Landau 2005, 2012; Regier \& Zheng 2007). In other words, according to scholars, Goals tend to attract our perceptual attention and be more pragmatically relevant than Sources. $^{3}$

The present article, along with other contributions to this thematic volume, aims to explore the role of language-specific characteristics, which previous studies have often left unexplored, in the expression of Sources and Goals. In order to address this issue, we compare two languages, German and Polish, which display some similarities: both are satellite-framed (Talmy 1985, 2000), and thus rely on grammatical morphemes to encode Path of motion, but also some differences in the morphosyntactic resources available for the expression of motion events (for a comparative study of German and Polish, see e.g. Fagard et al. 2013, Lewandowski \& Mateu 2016, Lewandowski 2018).

The questions we would like to explore in this paper are the following: how is Path - both simple (comprising one Ground with respect to which motion is performed) and complex (including two Grounds or more) - expressed in these two languages? Do German and Polish speakers express Source and Goal with the same regularity and the same degree of semantic

\footnotetext{
${ }^{3}$ For the discussion and summary of the literature on Source-Goal asymmetry, see e.g. Kopecka \& Ishibashi (2011), Narasimhan et al. (2012), Kopecka and Vuillermet (this vol.).
} 
specificity, or do they differ in the way they represent them linguistically? To which sequence of the motion event, initial and/or final, do they allocate more attention in their descriptions of motion? In order to investigate these questions, we examine descriptions of self-agentive (or spontaneous as opposed to caused) motion, collected with a set of visual stimuli, which ensures the comparability of the data. Our corpus includes descriptions of Goal-oriented events consisting of motion directed toward a final location, as in (1), Source-oriented events consisting of motion away from an initial location, as in (2), and some more complex motion events comprising two or three reference locations.

(1) Goal-oriented events

a. German

eine Frau läuft auf einen Baum zu

a.NOM.F.SG woman walk.PRS.3SG to a.ACC.M.SG tree to

'A woman walks up to a tree.' \{traj061_ger012\}

b. Polish

kobieta do wode-szła do drokiego drewa

woman.NOM.F.SG up.to-walk.PST.F.3SG to high.GEN.M.SG tree.GEN.M.SG

'A woman walked up to a big tree.' $\{$ traj061_pol01\}

(2) Source-oriented events

a. German

ein Junge kommt aus einer Höhle heraus

a.NOM.M.SG young.man come.PRS.3SG out a.DAT.F.SG cave hither.out

'A young man comes out of a cave.' \{traj028_ger013\} 
b. Polish

chtopiec wy-biegt $\quad$ morza

boy.NOM.M.SG out-run.PST.M.3SG from sea.GEN.N.SG

'A boy ran out of the sea.' \{traj031_pol007\}

The paper is organized as follows. In Section 2, we present our methodology, the data that we collected to carry out this study, and the participants who took part in data collection. In Section 3, we provide an overview of the morphosyntactic resources used by speakers of German and Polish in descriptions of motion events, with a specific attention to the lexical and grammatical devices found in the expression of the Path. Sections 4 and 5 investigate the types of asymmetries found in descriptions of Source-oriented and Goal-oriented events. In particular, in Section 4, we examine the expression of Path and its initial and final components. In Section 5, we investigate the expression of Grounds and examine to which reference location of the event, Source or Goal, speakers of German and Polish allocate more attention; in order to do so, we examine the frequency of the explicit encoding of Source and Goal in descriptions of simplex and complex Path and their semantic granularity. The article concludes with a summary of inter-linguistic and intra-linguistic variation in Source-oriented and Goal-oriented events and a discussion of the (a)symmetry in the expression of the two event types in German and Polish data.

\section{Methodology}

The data investigated in this paper were collected with native speakers of German and native speakers of Polish using the Trajectoire visual stimuli set (Ishibashi et al. 2006), which comprises 76 video-clips, of which 55 were designed for eliciting Path expressions (for a detailed description of the material, see Ishibashi 2015, Vuillermet \& Kopecka 2019, and Kopecka \& Vuillermet, this 
vol.). For German, we gathered the data in Tübingen, from 19 speakers including 12 women and 7 men, aged between 21 and 25 . All but one were students in humanities. ${ }^{4}$ They studied up to three foreign languages (English, French, Portuguese and/or Polish) but none of them was bilingual. For Polish, we gathered the data in Cracow, from 14 speakers, including 11 women and 3 men. As in the case of German, all the participants were students in humanities, aged between 19 and 25 . While studying one or two foreign languages (English, German, French and/or Russian), none of the participants was bilingual, or used two languages in everyday life. In both languages, the data were audio-recorded, transcribed, and coded for the purpose of the analysis. In total, the dataset comprises 1,045 motion descriptions in German and 770 motion descriptions in Polish.

Our aim being to compare the way German and Polish speakers describe Sources and Goals, for the purpose of this paper, we selected a series of simple Path and complex Path scenarios; this comprises $(i)$ eight Source-oriented events which imply motion from or away from the initial location, (ii) eight Goal-oriented events which imply motion to or toward the final location, (iii) two events which are both Source- and Goal-oriented comprising motion from an initial to a final location, and $(i v)$ one Source-Medial-Goal event consisting of motion from an initial via a medial to a final location (cf. Jackendoff 1983 and Kopecka \& Vuillermet, this vol. for the distinction between different kinds of Paths). Table 1 below lists the scenes selected for this study.

\footnotetext{
${ }^{4}$ In the case of one participant, the data were collected in Lisbon, Portugal, and one was 60 years old.
} 
Table 1.Event types selected for the study, including scene codes $(F=$ woman, $M=$ man, $C=$ child, $\mathrm{LR}=$ from left to right, $\mathrm{RL}=$ from right to left, back $=$ away from the camera, front $=$ toward the camera).

\begin{tabular}{ll}
\hline SOURCE-ORIENTED MOTION & GOAL-ORIENTED MOTION \\
\hline 023_Path_F_walk_outof_cave_front & 054_Path_F_walk_into_cave_front \\
025_Path_F_walk_outof_cave_back & 053_Path_F_walk_into_cave_back \\
027_Path_F_walk_outof_woods_sideRL & 057_Path_F_walk_into_woods_sideLR \\
031_Path_M_run_outof_sea_sideRL & 059_Path_C_run_into_sea_sideRL \\
032_Path_F_walk_awayfrom_tree_front & 061_Path_F_walk_toward_tree_back \\
038_Path_F_walk_outof_field_sideRL & 069_Path_F_walk_into_field_sideLR \\
035_Path_M_walk_awayfrom_F_front & 036_Path_M_walk_toward_F_back \\
055_Path_M_walk_out of_woods_front & 026_Path_M_walk_into_woods_back \\
\hline SOURCE-GOAL MOTION & \\
\hline 064_Path_C_jump_from_cliff_into_water_sideLR & \\
075_Path_C_jump_from_rock_to_rock_side & \\
\hline SOURCE-MEDIAN-GOAL MOTION & \\
\hline 060_Path_M_walk_out_cave_pass_walk_into_cave_side
\end{tabular}

We selected these scenes (rather than others) on the basis of the presence of a clearly perceptible Ground, at the beginning, at the end or at both the beginning and the end of a given motion event. Furthermore, for Source-oriented vs. Goal-oriented events, we chose only those scenes which display a clear symmetry as far as the Path followed by the Figure with respect to the Ground (i.e. reference location) is concerned. This includes pairs of events - eight Source-oriented and eight Goal-oriented - which display a similar physical setting and wherein only the direction differs, away from a Source location vs. toward a Goal location. It is important to note, however, that while the above-mentioned scenes were selected for the specific directionality of motion displayed in the video-clip, speakers may conceptualize them differently by choosing a perspective, which is different from what is foregrounded in the video itself. Furthermore, some motion descriptions may comprise two components of Path, and this even when motion in the video-clip was performed with respect to one reference location only. 
Altogether, the dataset under analysis in this study comprises 361 event descriptions in German (19 scenes $\times 19$ speakers) and 266 event descriptions in Polish (19 scenes $\times 14$ speakers). Note that while the data examined here are merely based on a visual elicitation task and, thus, are not pragmatically contextualized, the method we used to carry out the study not only ensures crosslinguistic comparability of the data but also serves to produce ecologically valid data, which are comparable to the data produced in spontaneous speech (see Vuillermet \& Kopecka 2019 for the discussion of the ecological validity of the Trajectoire stimuli set).

The linguistic resources - verbs, verb prefixes and particles, prepositions and case markers - used by the speakers in motion descriptions were coded and annotated. More specifically, each utterance was annotated for the kind of Path it describes, viz. SOURCE-ORIENTED, GOAL-ORIENTED, MEDIAL-ORIENTED, a combination of two or three of them or OTHER. Furthermore, the data coding comprises $(i)$ the encoding of the GROUND, typically as a noun (e.g. tree, cave, woods, sea), and (ii) the marking of the GROUND as SOURCE, GOAL or MEDIAL, typically with a preposition and a case marker (e.g. in Polish do 'to' + GEN, $w$ ‘in(to)' + ACC).

\section{Morphosyntactic resources in Source- and Goal-oriented motion descriptions}

Before investigating the types of (a)symmetries found in the data, we first provide an overview of the constructions and morphosyntactic resources used by German and Polish speakers to describe motion events, including simple and complex Path. As mentioned earlier, both German and Polish are prominently satellite-framed languages. As such, they rely on a variety of spatial grams (cf. Svorou 1994) to convey the Path and its components (e.g. verb prefixes and/or particles, prepositions, case markers), and typically use the verb to express Manner. Nevertheless, despite this shared typological feature, we will show that these languages also display some fine-grained lexical, morphosyntactic and semantic differences. 


\subsection{Morphosyntactic resources used in German}

In German, spatial information is typically distributed over satellites, prepositions and case markers. Satellites include a variety of items, mainly verb particles and verb prefixes, with differences in their morphosyntactic behavior (see e.g. Lüdeling 2001, Los et al. 2012). ${ }^{5}$ We will use here 'satellite' as a cover term for all such items (see Imbert et al. 2011 for the discussion of the satellite category within a functional-typological approach). Most German satellites convey a Path meaning, for example, ein 'in(to)', aus 'out'. German also has two deictic satellites, hin 'thither' and her 'hither', with an additional, reduced variant $r$ - which neutralizes this distinction (see e.g. Wunderlich 1983: 452, Dewell 2011: 38). ${ }^{6}$ These deictic satellites can be used alone, or be combined with Path satellites, ${ }^{7}$ thus yielding compound satellites, for instance hinauslaufen 'to run out (away from the deictic center)' or hereinkommen 'to come in (toward the deictic center)'. As has been noted in the literature, the deictic component of hin and her is sometimes bleached, ${ }^{8}$ namely in dialectal varieties of German, licensing constructions such as reingehen 'to go in (toward the deictic center)'. Behrens (2010), analyzing the productions of German-speaking children gathered with an elicitation tool, thus finds that "the hin/her distinction is not always realized" (ibid.: 56) and observes that "it is not clear whether [the participants] see this contrast as a deictic one" (ibid.: 65). She also notes that, according to Engelen (1995: 242), these satellites are

\footnotetext{
${ }^{5}$ For instance, Dewell (2011), after examining various über- 'above, over, across', um- 'around', unter- 'under' and durch- 'through, across' constructions, distinguishes between prefixes and particles. There is a morphosyntactic contrast between the two construction types, as well as a semantic contrast, for instance in their spatial uses (ibid.: 305 306). Lüdeling (2001) similarly distinguishes between particle verb constructions and preverb verb constructions. From a diachronic perspective, one could say that there is a continuum from 'loose' syntactic constructions (particle + verb) to morphological constructs (preverbs). In this study, since we are mostly interested in the semantic contribution of prefix (or particle) vs. verb root, we leave this distinction aside.

${ }^{6}$ This variant appears only in complex satellites, i.e. when the deictic satellite is combined with a path satellite, e.g. hinaus 'thither.out', heraus 'hither.out', raus '(hither).out'.

${ }^{7}$ Diachronically the last (and least grammaticalized) stratum of verb prefixation, according to Stevens (2011: 308).

${ }^{8}$ Wunderlich (1983: 454) thus writes that "An additional prefixing by her-, hin-, or $r$ - would, in these [local] cases, change nothing but add at most a deictic perspective" [our emphasis].
} 
mostly found in spoken language and, thus, are hardly discussed in grammars. We coded uses of simple satellites hin-, her- and $r$-, and uses of compound satellites such as, for example, hinaus 'thither.out', heraus 'hither.out', hinein 'thither.in' as instances of "deictic Path", i.e. they have a deictic meaning (which may be partly bleached) ${ }^{9}$ and may also be used by speakers to provide Path information.

The specificity of prepositions and case markers in German is that they convey the Path with reference to the Ground they introduce, as in (3), marking it as Source (aus einer Höhle 'out of a cave') or as a Goal (in die Höhle wieder ein 'into the cave again'), with or without a satellite. Specifically, in this example, the preposition aus 'out.of' and the dative case convey the meaning of motion out of a Source location without a satellite, whereas the preposition in 'in(to)', the accusative case on die Höhle 'the.ACC cave' and the satellite ein 'into' combine to convey the meaning of motion into a Goal Ground.

(3) Source-Goal event

ein Mann geht aus einer Höhle an
a.NOM.M.SG man go.3SG out.of a.DAT.F.SG cave by
einem $\quad$ Korb vorbei und in die Höhle
a.DAT.N.SG basket by and in the.ACC.F.SG cave
wieder rein auf der anderen seite
again in on the.DAT.F.SG other.DAT.SG side
'A man goes [or walks] out of a cave, by a basket and back into the cave on the other
side.' \{traj059_ger19\}

\footnotetext{
${ }^{9}$ According to Dewell (2011: 39), "adding the deictic particle does not substantially change the meaning of the basic path particle" but they "ground the event more in a particular spatial situation [...] emphasizing the directed nature of a path toward a goal".
} 
Verbs typically convey either Manner of motion (cf. De Knop \& Gallez 2013 op cit. [VV: please avoid op cit. referencing in favour of exact year: page referencing (more reader friendly)]), as in (4) (e.g. laufen 'to run, to walk', rennen 'to run', schlendern 'to walk leisurely') or Deixis (kommen 'to come', gehen 'to go'), as in (3). Combining with verbs lexicalizing Manner or Deixis, satellites and prepositional phrases (with case marking) thus play a major role in the marking of Source and Goal.

Source-Goal event

\begin{tabular}{|c|c|c|c|c|}
\hline ein & kleiner & Junge & rennt & vom \\
\hline a.NOM.M.SG & small.NOM.M.SG & boy & run.PRS.3SG & from.the.DAT.M.SG \\
\hline Strand aufs & & Meer & $z u$ & \\
\hline beach & rd.the.ACC.N.SG & sea & toward & \\
\hline
\end{tabular}

'A small boy runs from the beach toward the sea.' \{traj059_ger13\}

Besides satellites, German also has verbs conveying Path of motion, but the expression of Path in the verb alone is rather marginal, and less natural, as noted by De Knop \& Gallez (2013: 30). These include both morphologically simple verbs, such as (sich) nähern 'to approach, to come close(r)', and verbs with a [satellite + root] structure but with a Path meaning, which, in synchrony, is not clearly related to the satellite or the root, such as erretten 'to rescue'. The latter contain highly grammaticalized prefixes (e.g. er-,${ }^{10}$ ver-,${ }^{11}$ which cannot be said to have a simple Path meaning).

\footnotetext{
${ }^{10}$ The German prefix er-, from ur- 'from within out, out of' (Dewell 2015: 130), is extremely hard to gloss. Dewell notes that, while $e r$ - is "clearly meaningful in many typical uses", its meaning is "difficult to characterize", with two apparently "almost opposite meanings: an 'inchoative' one (erwachen ['wake up']) that adds a sense of origin and beginning, and a 'resultative' one (erkämpfen ['fight, get by fighting']) that adds a sense of concluding and reaching a goal" (ibid.: 3), two meanings which can be reconciled by the idea that "the beginning of a state can be seen as the conclusion of a goal-directed process that causes the new state to emerge" (ibid.: 128). $E r$ - thus "profiles the attainment of a goal space by a process that begins as a backgrounded run-up process, including one that emerges from beneath the surface of a host noun" (ibid.: 229).

${ }^{11}$ If possible, the case of the German prefix ver- (from prefixes meaning 'out', 'past' and 'away', see Pfeifer et al. 1993) seems even more desperate, to the point that Dewell asks jokingly "Are ver- verbs really just a disorganized
} 


\section{Benjamin Fagard \& Anetta Kopecka}

We found examples of both in our data, but their role in the expression of Path appears to be limited. For Source-oriented motion, we found only a few uses of verlassen 'to leave' and erscheinen 'to appear', which are arguably not genuine motion verbs. ${ }^{12}$ For Goal-oriented motion, we did not find many more verbs lexicalizing Path, only (sich) nähern 'to come close', and a few verbs which are not strictly speaking motion verbs, but can be used to convey motion, such as verschwinden 'to disappear' and sich erretten 'to flee, to move away (lit. to save oneself)'. As mentioned above, even when a verb could take on a Path meaning by itself, a satellite is present as well, thus making this Path component explicit. This is the case, for instance, with eindringen 'to force (one's way into)', which conveys Goal-oriented motion, as in (5), and durchqueren 'to cross (through)', which conveys Medial-oriented motion, as in (6). Some prefixes are lexicalized with the verb, resulting in semantic opacity, i.e. the meaning of the prefix and the meaning of the verb are indistinguishable (Lüdeling 2001), as in verschwinden 'disappear'.

Besides Path verbs mentioned above, the deictic verbs kommen 'to come' and gehen 'to go' may also be used to indicate Path (cf. Talmy 2000: 53-57, for whom Deixis is one of the three subcomponents of Path). As we did for deictic satellites, we coded the uses of kommen and gehen as instances of "deictic Path".

Goal-oriented event

ein Herr dringt ein in den Bambuswald

a.NOM.M.SG gentleman force.PRS.3SG into in the.ACC.M.SG bamboo.forest

'A man forces his way into the bamboo forest' \{traj026_ger01\}

hodgepodge of separate variants that have nothing much in common?" (ibid.: 5). Noting that "Ver- is certainly the most difficult prefix to relate to a single schematic meaning that might plausibly underlie its range of typical uses" (ibid.: 178), Dewell suggests that ver- "profiles the loss of a [figure]'s status in its original setting" (ibid.: 229).

12 The verb verlassen may be used to describe a motion event. However, the focus is not on the spatial features but on other features of the event (e.g. aspectual features - see Aurnague (2011) for an analysis of French quitter 'to leave'). 
(6) Medial-oriented event

$\begin{array}{llll}\text { ein } & \text { Mann durchquert } & \text { zielgerichtet ein } & \text { Waldstück } \\ \text { a.NOM.M.SG man through.cross.PRS.3SG purposefully }{ }^{13} \text { a } & \text { wood.piece } \\ \text { 'A man walks through the woods purposefully' }\{\text { traj056_ger11\} } & \end{array}$

Regarding the distribution of Path information in verb clauses, in descriptions of scenes displaying a simple Path (i.e. motion with respect to one reference location), the most frequent constructions are those with only one Path element - there is thus, typically, one Path element per clause in our data. However, in a few descriptions, there are two or three Path elements in reference to simple Path events. While these elements may be distributed over different clauses, they can also appear in a single clause, as in example (7) below, or be linked to a single verb associated with various satellites, yielding a series of clauses relying on one verb, as in example (3) above.

From a semantic point of view, the typical distribution of spatial information follows the temporal unfolding of the event: first the Source, then the Medial, then the Goal, as in (3), or the Source and the Goal, as in (7). The same holds true in Polish (see section 3.2).

(7) Source-Goal event

\begin{tabular}{|c|c|c|c|c|}
\hline ein & Junge & springt & von & einer \\
\hline a.NOM.M.SG & boy & jump.PRS.3sG & from & a.GEN.F.SG \\
\hline ins & Mee & & & \\
\hline
\end{tabular}

'A boy jumps from a cliff into the sea.' \{traj064_ger04\}

${ }^{13}$ The literal translation of zielgerichtet would be 'goal-oriented'. 


\section{Benjamin Fagard \& Anetta Kopecka}

In the description of complex Path events, in which both reference locations are visually prominent and play a crucial role in a given context (e.g. jump from the cliff into the sea), Source and Goal are typically found within one verb clause, as in (7). Conversely, in the description of scenes displaying only one reference location, some speakers segment the event into two separated clauses, as in (8), thereby adding spatial information, which is not necessarily prominent in the video-clip.

(8) Source-Goal event

$\begin{array}{llcl}\text { ein } & \text { Bub kommt } & \text { am } & \text { Strand aus dem } \\ \text { a.NOM.M.SG boy come.PRS.3SG at.DAT.M.SG beach out.of the.DAT.N.SG } \\ \text { Meer und rennt } \quad \text { in Richtung Ufer } \\ \text { sea and run.PRS.3S in direction shore }\end{array}$

'At the beach, a boy comes out of the sea and runs toward the shore' \{traj031_ger03\}

\subsection{Morphosyntactic resources used in Polish}

As in German, spatial information in Polish is typically encoded in satellites (i.e. verb prefixes) which convey Path of motion, and prepositional phrases, including prepositions and case markers, which introduce the Ground and mark it as either Source as in (9) or Goal as in (10).

(9) Source-oriented event

$\begin{array}{llll}\text { mężczyzna } & \text { wy-chodzi } & z & \text { lasu } \\ \text { man.NOM.M.SG } & \text { out-walk.PRS.3SG } & \text { from } & \text { forest.GEN.M.SG }\end{array}$

'The man is walking out of the forest.' $\{$ traj055_pol11\} 
(10) Goal-oriented event

$\begin{array}{llll}\text { chłopak } & \text { w-chodzi } & \text { leśna } & \text { gestwine } \\ \text { man.NOM.M.SG in-walk.PRS.3SG in wooded.ACC.F.SG } & \text { thicket.ACC.F.SG } \\ \text { 'The man is walking into a wooded thicket.' }\{\text { traj026_pol02\} }\end{array}$

In most cases, the verb prefix and the prepositional phrase are semantically congruent in that they are combined to express the same directionality of motion: in (9), the prefix wy- 'out' together with the preposition $z$ 'from' + GEN conveys the meaning of motion away from the initial location (forest), while in (10), the prefix $w$ - 'in' together with the preposition $w$ 'in' + ACC conveys the meaning of motion directed into the final location (forest brushwood). However, verb prefix and prepositional phrase can also express different components of the Path, as is the case in the example (11) below where the prefix wy- 'out' co-occurs with the preposition $n a$ 'on' + ACC. In such cases, the prefix typically expresses the Source while the prepositional phrase expresses the Goal. The inverse distribution of meaning, although possible in some contexts, has not been found in our dataset.

(11) Source-Goal event

chtopiec ny-chodzi namienie

boy.NOM.M.SG out-walk.PRS.3SG on stone.ACC.M.PL

'The boy walks out onto the stones.' \{traj028_pol02\}

Since the verb typically conveys Manner of motion, satellites and prepositional phrases play an important role in the representation of motion events in Polish, making a distinction between Source-, Medial-, and Goal-oriented events (cf. Kopecka 2010, 2012; Lewandowski 2014; Łozińska 2018). Note, however, that our dataset also reveals the use of verbs such as oddalić się 'to move.away REFL' and zbliżyć się 'to approach, move toward (lit. to move.toward REFL)', which 
respectively convey the meaning of Path oriented away from a Source as in (12) and toward a Goal as in (13). ${ }^{14}$ Yet, these verbs are not frequent in our data, and their use seems to characterize the idiolect of some speakers only, at least in this dataset.

(12) Source-oriented event

chtopak oddalasię lezacej od dziewczyny

boy.NOM.M.SG move.away.PRS.3SG_REFL from lying.GEN.F.SG girl.GEN.F.SG

'The boy is moving away from the girl, [who is] lying down.' \{traj035_pol14\}

(13) Goal-oriented event

chtopak zbliżytsię_dolezacej dziewczyny

boy.NOM.M.SG move.toward.PST.3SG.M_REFL to lying.GEN.F.SG girl.GEN.F.SG

'The boy moved toward the girl, [who was] lying down.' \{traj036_pol14\}

While the constructions with one Ground element per verb clause, such as those shown above, are the most common in the Polish data, Source and Goal can also be encoded together in a single verb clause. In such cases, the typical distribution of spatial information follows the temporal unfolding of the event with the initial Ground expressed before the final Ground, as in (14). Note that, in this particular example, the verb skoczyć 'to jump' is combined with the Source prefix $z-$ 'of'. Although possible, as illustrated in (15), temporally non-iconic expressions of the similar event are less frequent in our data. In this example, the verb skoczyć 'to jump' is combined with the Goal prefix $w$ - 'in', and the final Ground of the event is expressed prior to the initial Ground.

\footnotetext{
${ }^{14}$ Historically, the verbs oddalić się 'to move.away' and zbliżyć się 'to move.toward' are morphologically complex: they have been formed by adding a prefix - od- 'away' and $z$ - 'sociative' respectively - and a verbalizing suffix to a non-verbal element encoding distance. In contemporary Polish, however, they are interpreted as single lexical items (cf. Kopecka 2010). Although the translation of these verbs into English may suggest a deictic reading, their use in Polish is independent of the speaker's point of view. Furthermore, while their use is common in reference to animate Figures, they can also be used in reference to some non-animate objects (e.g. vehicles).
} 
(14) Source-Goal event

chtopiec ze-skoczyt $z$ klifu do wody

boy.NOM.M.SG of-jump.PST.3SG.M from cliff.GEN.M.SG to water.GEN.F.SG

'The boy jumped from the rock to the water.' \{traj064_pol06\}

(15) Goal-Source event

chtopiec w-skoczyt do wody
boy.NOM.M.SG in-jump.PST.3sG.M to water.GEN.F.SG
wysokiej skaty
from high.GEN.F.SG rock.GEN.F.SG

'The boy jumped into the water from the high rock.' \{traj064_pol01\}

The expressions including Source and Goal in one verb clause, such as those mentioned above, are often found in descriptions of scenes in which two Grounds are brought to the fore (e.g. jump from the cliff into the sea). In other contexts, speakers sometimes include another Ground, typically the Medial. Interestingly, in such descriptions, they tend to segment the event into two verb clauses and convey one Ground per clause. This is the case in (16) where the first clause conveys the meaning of intermediary (Medial) Path and the second clause the meaning of final (Goal) Path. ${ }^{15}$

\footnotetext{
15 The Trajectoire data suggest that Source and Goal combine together in one verb clause more easily than they do with Medial, which tends to be encoded in a separate verb clause. This issue should be investigated in more detail on a larger corpus of data.
} 
18 Benjamin Fagard \& Anetta Kopecka

(16) Medial-Goal event

\begin{tabular}{|c|c|c|}
\hline dziewczyna & prze-chodzi & polane \\
\hline girl.NOM.SG & across-walk.PRS.3SG & meadow.ACC.F.SG \\
\hline$w$-kracza & krzaki & \\
\hline
\end{tabular}

'The girl walks across the meadow and steps into the bushes.' \{traj069_pol09\}

Now that we have outlined the morphosyntactic resources and the type of constructions used by the speakers of German and Polish, let us turn to the issue of Source-Goal asymmetry. We have seen that German and Polish show both similarities (e.g. they are satellite-framed and express Path in grammatical morphemes) and language-specific characteristics (e.g. in contrast to Polish, German has deictic verbs of motion and deictic satellites, which combine with Path satellites) as far as the expression of motion is concerned. What is the impact of these characteristics on the way speakers of German vs. Polish describe Source and Goal of motion? Do they depict these segments of Path in a similar or a different way? To which component, Source or Goal, do they allocate more attention when encoding simple vs. complex Path events? To address these questions, we first examine the expression of Source-oriented and Goal-oriented Path conveyed by Path satellites and/or Path verbs, then explore the expression of Source and Goal Grounds in prepositional phrases. Although the presentation of the data sometimes refers to the Medial component of the Path, we do not investigate its expression in detail in this paper, our main aim here being to uncover the expression, symmetrical or asymmetrical, of Source and Goal. 


\section{Source-Goal (a)symmetry in Path expression}

As a core component of motion events (Talmy 2000), Path is essential to define the direction in which motion is performed and its orientation with respect to the Ground (Source, Medial or Goal). As has been shown in Section 3, in both German and Polish, Path is typically expressed by satellites, but both languages also have a few verbs which convey directionality. In this section, we address the issue of simple vs. complex Path in motion descriptions in our datasets. By doing so, our aim is to examine how speakers of the two languages describe Source-oriented Path and Goal-oriented Path, in a symmetrical or asymmetrical way, and to investigate inter-linguistic and intra-linguistic differences in the structural and conceptual choices they make when describing these two event types.

\subsection{Path in Source-oriented vs. Goal-oriented motion events}

Let us look first at descriptions of simple Path events, which imply motion with respect to one Ground, i.e. motion from or away from a Source and motion to or toward a Goal (cf. Table 2, Section 2). The results in Table 2 show the proportion of the explicit encoding of Path in satellites and verbs. As we can see, while the tendency to encode Path in satellites is strong in both languages, their frequency of use varies in speakers' descriptions of motion: in Polish, their proportion is very high and accounts for $84.4 \%$ of motion descriptions, whereas in German, counting Path satellites used with both Manner and Path verbs, it represents $69.8 \%$ in total (a statistically significant difference: $\chi^{2}=15.1, d f=1, p<.01^{* *}$ ) [VV: here \& henceforth: the standard way of reporting chi-square test results is to include the degrees of freedom between the $\chi$ and $p$ values, so I have added the slots (highlighted to make them immediately visible) for you to simply fill in for each result]. Note that the co-occurrence of Path satellites with Path verbs is 
the most frequent pattern found in the German data. Furthermore, in both languages, there are also cases where speakers express Path in the verb alone (rather than in the satellite) such as, for example, sich nähern 'to come close(r)' in German, or wracać 'to return' in Polish, which conveys the meaning of coming or going back, a notion for which Polish does not have a dedicated prefix. The expression of Path in the verb is much more frequent in German than in Polish: it accounts for $56.3 \%(\mathrm{~N}=92)$ of simple Path events in German (including both the verb alone and the verb combined with a Path satellite) and only 9.8\% ( $\mathrm{N}=22)$ in Polish (a statistically significant difference: $\left.\chi^{2}=31.8, d f=1, p<.01 * *\right)$.

Table 2. Locus of Path encoding in German and Polish. ${ }^{16}$

\begin{tabular}{|c|c|c|c|c|c|}
\hline Languages & Path in sat & Path in V & Path in SAT \& V & Other & Total \\
\hline & $27 \%$ & $13.5 \%$ & $(130)$ & $16.8 \%$ & $100 \%$ \\
\hline Polish & $84.4 \%$ & $9.8 \%$ & - & $5.8 \%$ & $100 \%$ \\
\hline
\end{tabular}

The difference we observe in terms of locus is closely related to the relevance of "deictic Path" in German and its absence in Polish. As presented in section 3.1, in addition to the deictic satellites hin- 'thither' and her- 'hither', German also has two verbs encoding deixis, gehen 'to go' and kommen 'to come'. Although their deictic meaning is very sensitive to the context, their use is frequent in our dataset. When Path is encoded in the verb in German, it is generally with kommen and gehen (93\% of cases); similarly, the deictic satellites are often present when Path is encoded in a satellite $(63.7 \%$ of cases $)$.

It is important to note that, in German, Path can also be encoded in a prepositional phrase alone, with a simple Manner verb which is not associated with a satellite, as in example (17) below. Spatial information is given here by both the preposition in 'in, into' and the accusative case

\footnotetext{
${ }^{16}$ In tables providing information on the locus of Path encoding, we do not distinguish between "Path" proper and "deictic Path".
} 
marking on the determiner (das 'the.N.ACC'), which disambiguates between the two meanings of German in, locative (in + DAT) and allative (in + ACC).

\begin{tabular}{|c|c|c|c|c|}
\hline (17) ein & Junge & rennt & das & \\
\hline a.NOM.M.SG & boy.NOM & run.PRS.3SG in & the.ACC.N.SG & sea \\
\hline
\end{tabular}

Aside from structural choices that speakers make for encoding Path - i.e. in the satellite, in the verb and/or in the prepositional phrase -, the data also show that some speakers tend to conceptualize some scenarios as an activity rather than as a change of location; this is the case in the Polish example (18), which shows the use of the verb kapać się 'take bath, swim' and the locative prepositional phrase describing the place where the activity happens.
(18) chtopak
'The boy is swimming in the sea alone. $\left\{\right.$ traj $059 \_$pol8 $\}$

Looking now at descriptions of Source-oriented and Goal-oriented events separately, Tables 3 and 4 show some further inter-linguistic differences. The German data (Table 3) reveal that speakers have different encoding preferences with regard to these two event types. For the description of Source-oriented events, they tend to use Path satellites combined with Path verbs $(56.6 \%$ in Source-oriented events vs. $28.9 \%$ in Goal-oriented events, i.e. roughly twice as much as in Goaloriented event), while for the description of Goal-oriented events, they are more often inclined to use Path satellites combined with Manner verbs (34.9\% in Goal-oriented events vs. $19.1 \%$ in Source-oriented event, i.e. almost twice as much as in Source-oriented events; a statistically significant difference: $\left.\chi^{2}=9.6, d f=1, p<.01 * *\right)$. A further difference between Source-oriented and Goal-oriented event descriptions in German is the use of deictics (both verbs and satellites) to 
indicate Path, which is much more frequent in Source-oriented events than in Goal-oriented events (a statistically significant difference: $\chi^{2}=13.2, d f=1, p<.01^{* *}$ ). In Polish (Table 4), there is no difference in the type of linguistic resources used by the speakers in encoding these two event types: the use of Path satellites with Manner verbs consists of $84.8 \%$ in Source-oriented events and $83.9 \%$ in Goal-oriented events (not statistically significant difference: $\chi^{2}=0.03, d f=1$, $\left.\mathrm{p}>0.1^{\mathrm{ns}}\right)$.

Table 3. Locus of Path encoding in Source- vs. Goal-oriented events in German

\begin{tabular}{lllllllllll}
\hline Event type & \multicolumn{2}{l}{ Path in SAT } & \multicolumn{2}{l}{ Path in V } & \multicolumn{3}{l}{ Path in SAT \& V } & Other & \multicolumn{3}{c}{ Total } \\
\hline Source-oriented & $19.1 \%$ & $(29)$ & $14.5 . \%$ & $(22)$ & $56.6 \%$ & $(86)$ & $9.9 \%$ & $(15)$ & $100 \%$ & $(152)$ \\
Goal-oriented & $34.9 \%$ & $(53)$ & $12.5 \%$ & $(19)$ & $28.9 \%$ & $(44)$ & $23.7 \%$ & $(36)$ & $100 \%$ & $(152)$
\end{tabular}

Table 4. Locus of Path encoding in Source- vs. Goal-oriented events in Polish.

\begin{tabular}{lllllcllll}
\hline Event type & \multicolumn{2}{l}{ Path in SAT } & \multicolumn{2}{l}{ Path in V } & Path in SAT \& V & Other & \multicolumn{3}{c}{ Total } \\
\hline Source-oriented & $84.8 \%$ & $(95)$ & $7.1 \%$ & $(8)$ & - & $8 \%$ & $(9)$ & $100 \%$ & $(112)$ \\
Goal-oriented & $83.9 \%$ & $(94)$ & $12.5 \%$ & $(14)$ & - & $3.6 \%$ & $(4)$ & $100 \%$ & $(112)$
\end{tabular}

The difference between German and Polish is not limited to the frequency of specific linguistic strategies used for Path expression in Source- and Goal-oriented-events. The data also reveal differences in the diversity of Path satellites and Path verbs, and in morphological complexity of Path satellites.

First, regarding Path satellites, while they are in general less frequent in the German data, they are nevertheless more diverse than in Polish. As Tables 5 and 6 show, to encode similar simple Path events, German speakers used 22 distinct Path satellites, some of which are morphologically simple and others morphologically complex, whereas Polish speakers used only seven satellites, all morphologically simple. 
Furthermore, as mentioned above, Path satellites in German are often combined with the deictic satellites hin 'away (from the deictic center)' and her 'toward (the deictic center)'. This combinability between deictic and Path satellites contributes to the overall diversity of resources in German and shows the importance of the observer's point of view when describing motion events.

Finally, the German data differ in the diversity of Path satellites used in descriptions of Source-oriented vs. Goal-oriented events (Table 5). We found 14 different Path satellites in descriptions of Goal-oriented events (e.g. aus 'out', hinein 'thither.in', hin 'thither'), of which only three or four are really frequent (hinein 'thither.in', $z u$ 'to(ward)', rein 'in', zurück 'back'). In descriptions of Source-oriented events, we found 16 different Path satellites (e.g. heraus 'hither.out', zurück 'back', her 'hither'), of which only five are frequent (heraus 'hither.out' and raus 'out', $z u$ 'to(ward)', weg 'away', and hinaus 'thither.out').

As can be seen in Table 5, some of these satellites are used in the expression of both event types. In Source-oriented events, the most frequent satellite is by far aus 'out', mostly used as part of a complex satellite, e.g. a combination of deictic her 'hither' and aus 'out'. Another, less frequent option is the use of weg 'away', a satellite grammaticalized from the noun Weg 'way'. In Goal-oriented events, the most frequent satellite is ein 'in', which is generally combined with the deictic satellite hin 'thither', followed by $z u$ 'to' and zurück 'back' (grammaticalized from the preposition $z u$ 'to, toward' and the noun Rück 'back'). 
Table 5. Satellites in simple Path events in German ${ }^{17}$

\begin{tabular}{|c|c|c|c|}
\hline Path type & Item & $\begin{array}{c}\text { Source-oriented } \\
\text { events } \\
(\mathrm{N}=137)\end{array}$ & $\begin{array}{c}\text { Goal-oriented } \\
\text { events } \\
(\mathrm{N}=107)\end{array}$ \\
\hline \multirow{4}{*}{ out } & heraus(-) 'hither.out' & 60 & \\
\hline & $\operatorname{raus}(-)$ 'out' & 24 & \\
\hline & hinaus(-) 'thither.out' & 8 & \\
\hline & $\operatorname{aus}(-)$ & 2 & 3 \\
\hline \multirow{3}{*}{ in } & hinein(-) 'thither.in' & & 32 \\
\hline & rein(-) 'in' & & 16 \\
\hline & ein(-) 'in' & & 1 \\
\hline \multirow{3}{*}{ to } & $z u(-)$ 'to' & $22^{18}$ & 33 \\
\hline & $\operatorname{hinzu(-)}$ 'thither.to' & & 1 \\
\hline & weg(-) 'away' & 21 & 1 \\
\hline away & $\begin{array}{l}\text { davon(-) 'away (lit. } \\
\text { there.from)' } \\
\text { ent- 'away, forth' (prefix) }\end{array}$ & 1 & 1 \\
\hline back & zurück(-) 'back' & 3 & 9 \\
\hline \multirow{2}{*}{$\begin{array}{l}\text { along } \\
\text { forward }\end{array}$} & entlang(-) 'along' & 2 & 3 \\
\hline & hervor(-) 'hither.forward' & 4 & \\
\hline \multirow[t]{2}{*}{ through } & $\begin{array}{l}\text { hindurch(-) } \\
\text { 'thither.through' }\end{array}$ & 1 & 2 \\
\hline & durch- 'through' (prefix) & 2 & 1 \\
\hline \multirow[t]{2}{*}{ against } & entgegen 'against' & 2 & \\
\hline & rüber(-) 'hither.over' & 1 & \\
\hline over & über- 'over' & 4 & 3 \\
\hline \multirow{2}{*}{ deixis } & $\operatorname{hin}(-)$ 'thither' & & 1 \\
\hline & her(-) 'hither' & 1 & \\
\hline
\end{tabular}

In contrast to German, the Polish data reveal no difference in the diversity of satellites used in the encoding of Source- vs. Goal-oriented events. As Table 6 below shows, we found six Path prefixes in descriptions of Source-oriented and six in descriptions of Goal-oriented events. Note that most prefixes were used, with varying frequency, in the expression of both event types. This is merely due to the fact that some speakers conceptualize the orientation of certain events differently from

\footnotetext{
${ }^{17}$ Numbers in Tables $5 \& 6$ differ from those given in others (e.g. Tables $2 \& 3$ ): they correspond to token counts. As a matter of fact, scene descriptions may contain various verb prefixes, as well as none at all.

${ }^{18}$ Often as part of a deictic construction such as auf mich zu 'toward me' ( 20 occurrences out of 22 in Source-oriented scenes, only one in Goal-oriented scenes).
} 
what might be expected, by encoding those aspects of the events which are backgrounded in individual motion scenes rather than those which are prominently shown. Nevertheless, such a change of perspective as regards Path of motion is scarce in our dataset, as evidenced by the difference in token counts (the congruent use of satellites, i.e. Source satellite in Source-oriented event or Goal satellite in Goal-oriented events, accounts for over $90 \%$ of tokens).

The two most frequent verb prefixes found in the Polish data are $w y$ - 'out' and $w$ - 'in', which convey the meaning of boundary-crossing at the initial and final location respectively. Motion from an initial location and to a final location with no boundary-crossing tend to trigger the use of the prefixes $o d$ - 'from, off' in Source-oriented events and pod- 'up.to, under' in Goal-oriented events.

Table 6. Satellites in simple Path events in Polish.

\begin{tabular}{lcc}
\hline Satellites & $\begin{array}{c}\text { Source-oriented } \\
\text { events } \\
(\mathrm{N}=94 / 112)\end{array}$ & $\begin{array}{c}\text { Goal-oriented } \\
\text { events } \\
(\mathrm{N}=91 / 112)\end{array}$ \\
\hline wy- 'out of' & 72 & 1 \\
$w$ - 'into' & 1 & 61 \\
pod- 'up.to, under' & 1 & 20 \\
od- 'from' & 16 & 1 \\
prze- 'across, through' & 2 & 6 \\
$z(e)$ - 'off' & 2 & - \\
po- 'away' & - & 2
\end{tabular}

As regards the use of verbs depicting Path, our data show that German speakers frequently rely on the verbs kommen 'to come' and gehen 'to go', sometimes using both in the same utterance. ${ }^{19}$ As is shown in Table 7, a few other verbs were found; the only one which appears more than three

\footnotetext{
${ }^{19}$ That these verbs are used not only to express deixis but also to indicate Path seems to be confirmed by the greater tendency for kommen 'to come' to appear in Source-oriented scenes (90\% of its occurrences in simple Path events) and for gehen 'to go' to appear in Goal-oriented events (62\% of its occurrences in simple Path events), revealing a statistically significant difference $\left(\chi^{2}=49.2, d f=1, p<.01 * *\right)$.
} 
times is queren 'to cross'; it is always used with a prefix (überqueren 'to cross over' and durchqueren 'to cross (lit.) through').

Table 7.Path verbs in simple Path events in German.

\begin{tabular}{lcc}
\hline Verbs & $\begin{array}{c}\text { Source-oriented } \\
(\mathrm{N}=108 / 152)\end{array}$ & $\begin{array}{c}\text { Goal-oriented } \\
(\mathrm{N}=63 / 152)\end{array}$ \\
\hline kommen 'to come' & 71 & 7 \\
gehen 'to go' & 23 & 48 \\
gehen + kommen 'to go + to come' & 8 & 2 \\
überqueren 'to cross' & 1 & 2 \\
sich entfernen 'to depart, to move away' & 3 & - \\
sich nähern'to approach' & - & 2 \\
durchqueren 'to cross' & 1 & 1 \\
zurückkehren 'to come back, to return' & - & 1 \\
verlassen 'to leave' & 1 & -
\end{tabular}

In Polish, the use of Path verbs is much less common than in German. As shown in Table 8, among the six Path verbs found in the Polish data, three were used in Goal-oriented events and five in Source-oriented events. Two of these verbs, wracać 'to return' and zblizyć się 'to approach', were used in the expression of both event types. The number of occurrences of individual verbs is very low in the Polish dataset, the most frequent verb being wracac 'to return'; note that this verb is insensitive to the orientation toward or away from the deictic center and, hence, can be used for both coming and going back.

Table 8. Path verbs in simple Path events in Polish.

\begin{tabular}{lcc}
\hline Verbs & $\begin{array}{c}\text { Source-oriented } \\
\text { events } \\
(\mathrm{N}=8 / 112)\end{array}$ & $\begin{array}{c}\text { Goal-oriented } \\
\text { events } \\
(\mathrm{N}=14 / 112)\end{array}$ \\
\hline wracać 'to return' & 2 & 9 \\
zbliżyć się 'to approach' & 2 & 2 \\
opuszczać 'to leave' & 2 & - \\
kierować się 'to head (somewhere)' & 1 & - \\
oddalać się 'to move away' & 1 & - \\
zniknaćc 'to disappear' & - & 3
\end{tabular}




\subsection{Path in complex Source-(Medial)-Goal events}

Let us now examine the expression of complex Path events, which consist of motion in relation to two or three Grounds, Source-(Medial)-Goal. In German and Polish, such complex events can be encoded in one, two or three verb clauses, depending on the aspects of the event that attract the speaker's attention, and the syntactic strategy they choose to segment the event. The segmentation of the event into one or more clauses may have consequences on the type of Path components which are foregrounded and those which are backgrounded. Hence, before addressing the issue of Source and Goal in complex Path expressions, let us first consider how speakers organize spatial information in the linguistic structure.

First, when describing the two Source-Goal events - jump from one rock to another, jump from cliff into water - there is a clear tendency in German and Polish to express both Grounds and encode them in one verb clause. Interestingly, when describing these events, German speakers tend not to encode Path explicitly in a satellite, as illustrated in example (19). Although the use of a satellite is possible in this context (e.g. with hinunter 'thither.down'), only a minority of speakers use such a strategy. The omission of the Path satellite in descriptions of these events also occurs in Polish, as can be seen in the example (20) in which the verb skoczyć 'to jump' occurs alone. The omission of the Path prefix in the context of these events is likely due to the choice of the verb, springen 'to jump' in German and skakać 'to jump' in Polish; in both languages, these verbs cooccur with two prepositional phrases, one conveying Source and the other conveying Goal, thus allowing to infer Path from the context.

(19) ein Junge springt von einer Klippe ins Meer a.NOM.M.SG boy jump.PRS.3SG from a.DAT cliff in.DET.ACC.N.SG sea 'A boy jumps from a cliff into the sea' \{traj064_ger04\} 
28 Benjamin Fagard \& Anetta Kopecka

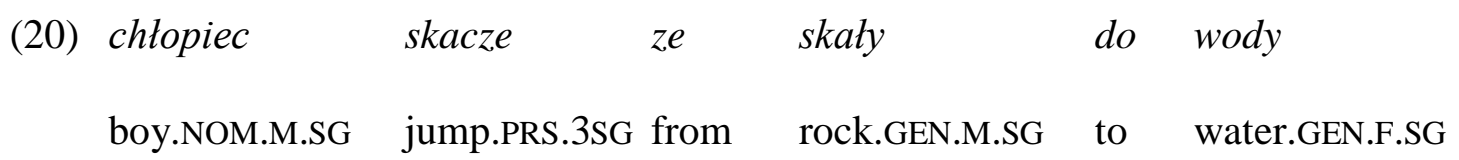

'The boy jumps from the rock into the water.' \{traj064_pol3\}

Nevertheless, while in the German data the omission of Path satellite is predominant, in Polish Path tends to be explicitly encoded in the verb prefix. This is shown in the example (21) wherein the verb skoczyć 'to jump' is combined with the prefix prze- 'across, over', which conveys the meaning of Path from initial, through medial, to final location, and which co-occurs with Source and Goal prepositional phrases.

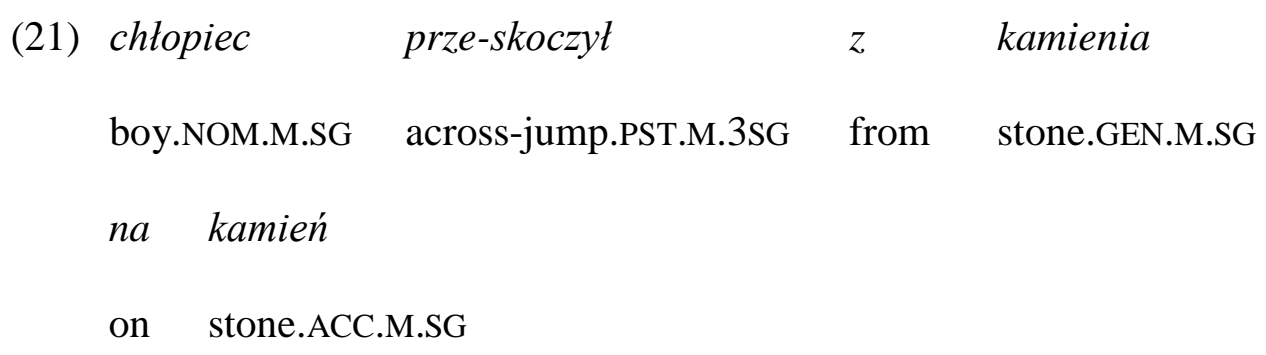

'The boy jumped (across) from one stone to another.' \{traj075_pol14\}

While descriptions of Source-Goal events reveal language-specific tendencies with regard to Path expression, less explicit (German) vs. more explicit (Polish), there seems to be more variation among speakers in how they depict the Source-Medial-Goal event - walk out of cave, past basket, into another cave - and the conceptual choices they make. Table 9 shows how speakers vary in the number and types of Grounds they express. In German, though some speakers do omit one element of the Path (typically the Source), most of them describe all three elements, providing highly detailed descriptions of the event (14 occurrences; cf. example (3), Section 3.1). In Polish, there is only one occurrence of the encoding of all three components of Path; instead, speakers resort to two other strategies and express either two Path components, typically Source and Goal 
(7 occurrences), or only one component, typically the Medial (6 occurrences). None of them combines Medial with Source or Goal.

Table 9. The encoding of Path in Source-Medial-Goal events.

\begin{tabular}{lcc}
\hline Path sequence & $\begin{array}{c}\text { German } \\
(\mathrm{N}=19)\end{array}$ & $\begin{array}{c}\text { Polish } \\
(\mathrm{N}=14)\end{array}$ \\
\hline Source + Medial + Goal & 14 & 1 \\
Source + Goal & - & 7 \\
Medial & 1 & 6 \\
Source + Medial & 1 & - \\
Medial + Goal & 3 & -
\end{tabular}

Depending on the number of Path sequences mentioned, speakers tend to use two or three verb clauses to describe this scene. In the German example (22), for instance, each segment of the Path has a dedicated clause, the first one for the Source, the second one for the Medial and the last one for the Goal, with another clause in between - unfinished - describing the trajectory of the Figure.

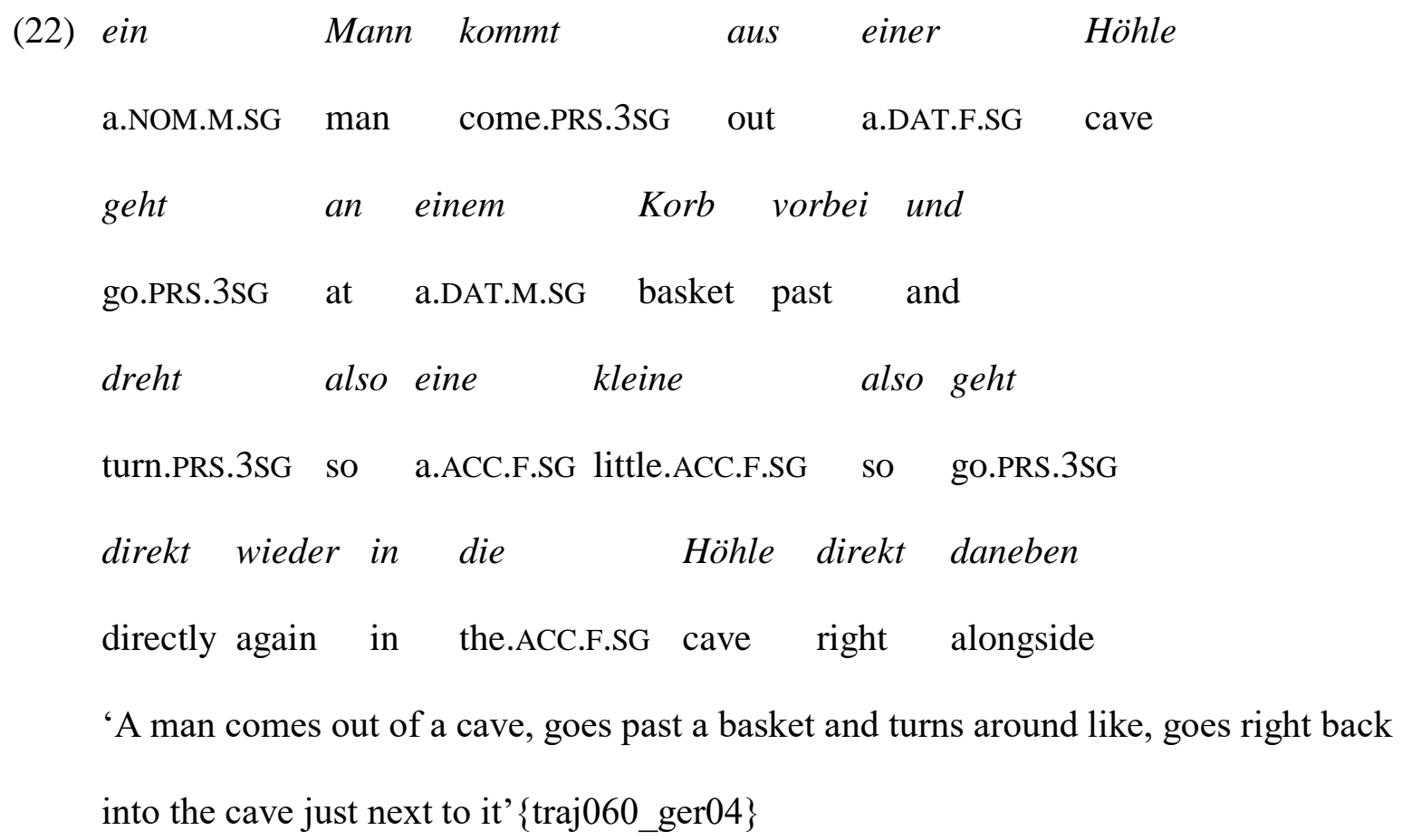


In the Polish example (23), the verb iść 'to walk', which is used in both clauses, occurs with the prefix $w$ - 'in' in the first clause to describe Goal-oriented Path, and with the prefix $w y$ - 'out' in the second clause to describe Source-oriented Path.

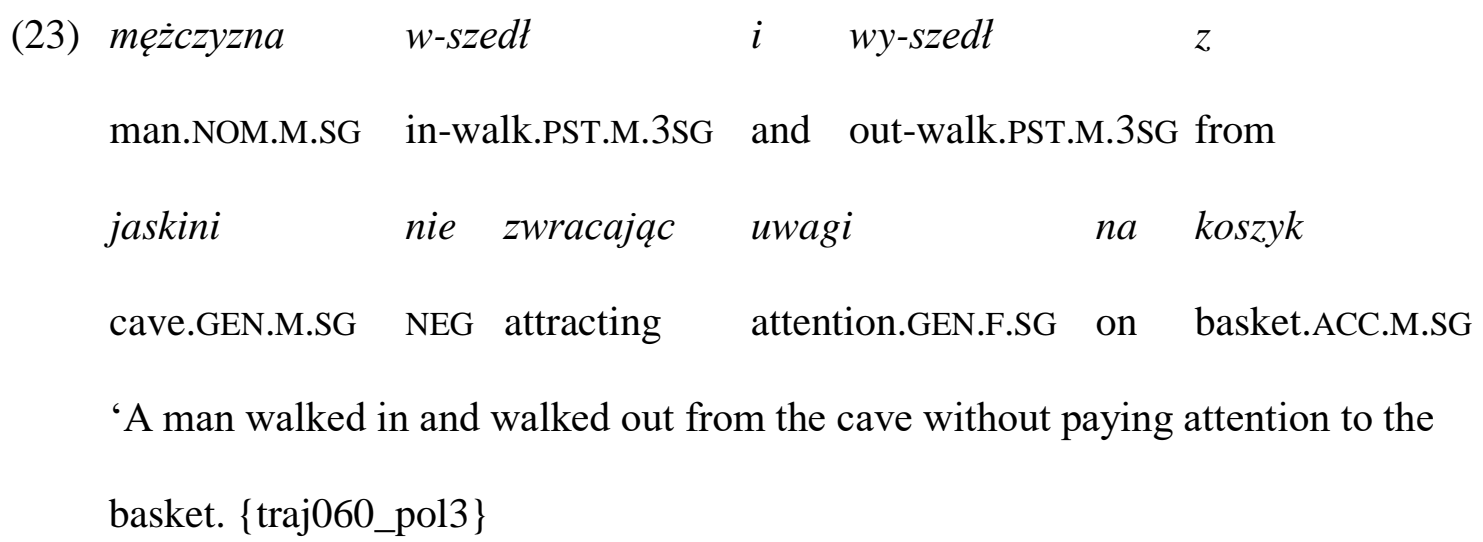

As we have seen earlier, German and Polish speakers have the possibility to express Source and Goal components in one verb clause; hence, one may ask why they choose a two clauses strategy to depict this scene. The reason for distributing spatial information between two clauses in this specific context may be the type of Ground (cave) which imply a boundary-crossing at both the initial and the final location. While motion from an open location (e.g. cliff) into an enclosed space (e.g. water), as in (19) and (20) above, can easily be conveyed in a single verb clause, there seems to be a structural constraint to convey motion from a bounded location into another bounded location within one verb clause. This constraint could actually explain - among other factors, such as whether the scene is perceived by participants to be natural or not - why speakers of the two languages tend to use multiple clause constructions to describe this complex Path event. Moreover, given that such multiclause constructions are syntactically heavier and, as is the case in Polish, imply the repetition of the same verb root (here the verb iść 'to walk') in different clauses, it may prompt speakers to omit one element of Path (typically the Medial) or, on the contrary, to express the Medial and to omit the Source and the Goal. 
The segmentation of complex Path events into one clause or more has consequences on both type and number of resources used. Looking first at the morphosyntactic locus selected to convey the Path in the expression of such events, including both Source-Goal events (jump from one rock to another, jump from cliff into water) and the Source-Medial-Goal event (walk out of cave, nearby the basket, into another cave), the difference between German and Polish in the use of Path satellites is greater than in the expression of simple Path events (cf. Section 4.1). Specifically, the tendency found for simple Paths - i.e. Polish speakers use Path prefixes more frequently than German speakers, who in turn more frequently rely on combinations of a Path verb and a Path satellite - is confirmed by descriptions of complex Paths. Table 10 shows that the expression of Path in a satellite amounts to $73.8 \%$ in Polish and only $21.1 \%$ in German (a statistically significant difference: $\left.\chi^{2}=27.4, d f=1, p<.01^{* *}\right)$. In fact, since German possesses different resources for Path encoding (satellites, verbs and the combination of the two), speakers use these resources with varying frequencies without being constrained to systematically choose one type of linguistic device.

Table 10. Locus of complex Path encoding in German and Polish.

\begin{tabular}{|c|c|c|c|c|c|}
\hline Languages & Path in SAT & Path in $\mathrm{V}$ & Path in SAT \& V & Other & Total \\
\hline & $21.1 \%$ & $15.9 \%$ & (11) & $43.8 \%$ & $100 \%$ \\
\hline Polish & $73.8 \%$ & - & - & $26.2 \%$ & $100 \%$ \\
\hline
\end{tabular}

Looking now at the type of satellites found in complex Path descriptions in German, we found a total of 9 different Path satellites (both simple and complex, see Table 11). The only (relatively) frequent satellite in complex Path descriptions is vorbei 'past' (see example (22) above). Other satellites mainly express the Goal, with or without deixis, for instance rein 'in' and hinein 'thither.in' or runter 'under' and hinunter 'thither.under'. In Polish (Table 12), three satellites only 
were found in descriptions of these events, the most frequent being the prefix prze- 'across, through'.

Table 11. Satellites in complex Path events in German.

\begin{tabular}{|c|c|c|c|}
\hline \multirow[b]{2}{*}{ Path type } & \multirow[b]{2}{*}{ Prefixes } & \multicolumn{2}{|c|}{ Complex Path } \\
\hline & & $\begin{array}{c}\begin{array}{c}\text { Source- } \\
\text { Goal } \\
(\mathrm{N}=7 / 38)\end{array}\end{array}$ & $\begin{array}{c}\text { Source-Medial- } \\
\text { Goal } \\
\qquad(\mathrm{N}=15 / 19)\end{array}$ \\
\hline out & raus 'out' & - & 2 \\
\hline \multirow{2}{*}{ in } & hinein 'thither.in' & 2 & 1 \\
\hline & rein 'in' & - & 3 \\
\hline past & vorbei 'past' & - & 7 \\
\hline \multirow[b]{2}{*}{ under } & runter 'under' & 3 & - \\
\hline & $\begin{array}{l}\text { hinunter } \\
\text { 'thither.under' }\end{array}$ & 1 & \\
\hline \multirow{2}{*}{ around } & um 'around' & - & 1 \\
\hline & rum 'around' & - & 1 \\
\hline deixis only & hin 'thither' & 1 & - \\
\hline
\end{tabular}

Table 12. Satellites in complex Path events in Polish.

\begin{tabular}{lcc}
\hline Prefixes & \multicolumn{2}{c}{ Complex Path } \\
& $\begin{array}{c}\text { Source- } \\
\text { Goal } \\
(\mathrm{N}=17 / 28)\end{array}$ & $\begin{array}{c}\text { Source-Medial- } \\
\text { Goal } \\
(\mathrm{N}=20 / 14)\end{array}$ \\
\hline prze- 'across, through' & 10 & 9 \\
$w$ - 'into' & 3 & 7 \\
$z$-'from' & 4 & 4
\end{tabular}

As we have seen earlier in the example (21), the prefix prze- 'across, through' highlights the whole Path followed by the Figure, from the initial via medial to the final location. As for the two other prefixes, $w$ - 'into' and $z$ - 'from', depending on the way the speaker conceptualizes the event, they each put emphasis on a different portion of Path: $w$ - 'in' emphasizes the final sequence of Path, as in (24), while $z$ - 'from' its initial sequence, as in (25). 
(24)
chtopiec
w-skoczyt
do wody
z wysokiej

boy.NOM.M.SG

in-jump.PST.M.3SG to

water.GEN.F.SG from high.GEN.F.SG

skaty

rock.GEN.F.SG

'The boy jumped into the water from a high rock'. \{traj064_pol1\}

(25)

chtopiec ze-skoczyt $\quad z \quad$ klifu do wody

boy.NOM.M.SG from-jump.PST.M.3SG from cliff.GEN.M.SG to water.GEN.F.SG

'The boy jumped from the cliff into the water'. \{traj064_pol6\}

Concerning the use of verbs, while Polish speakers never rely on verbs to describe Path in complex

Path events, in German we found 2 verbs used in the expression of Path in such events, as Table 13 shows: kommen 'to come' and gehen 'to go', which appear only in the Source-Medial-Goal event.

Table 13. Path verbs in complex Path events in German.

\begin{tabular}{lcc}
\hline Path Verb & \multicolumn{3}{c}{ Complex Path events } \\
& $\begin{array}{c}\text { Source-Goal } \\
(\mathrm{N}=0 / 38)\end{array}$ & $\begin{array}{c}\text { Source-Medial-Goal } \\
(\mathrm{N}=13 / 19)\end{array}$ \\
\hline kommen 'to come' & - & 13 \\
gehen 'to go' & - & 4
\end{tabular}

\subsection{Summary: Source-Goal asymmetry in Path expression}

The data presented in this section show typological similarities in the structure and type of linguistic resources used by speakers in both languages to describe the Path of motion: satellites, verbs, prepositions and case markers. However, there are also important differences in the way speakers use these resources to describe Source and Goal in German and Polish. These inter- 


\section{Benjamin Fagard \& Anetta Kopecka}

linguistic differences appear mainly in the degree of grammaticalization of satellites and, importantly, in the asymmetry between Source and Goal.

Firstly, the linguistic resources used by speakers to convey the Path are less frequent but more diverse in German, and more frequent but less diverse - in other words, more grammaticalized - in Polish. Specifically, Path satellites display a higher degree of grammaticalization in Polish, according to several of Lehmann's (2002) grammaticalization hallmarks. Namely, comparing the satellites in the two languages, we find in the Polish data a greater degree of paradigmatization (smaller set of forms), obligatorification (more frequent use), reduction (shorter forms), and boundedness (only non-separable prefixes).

Moreover, there is a greater degree of asymmetry in the use of these resources in Sourceoriented vs. Goal-oriented events in German as compared to Polish. This asymmetry is reflected in both the use of Path satellites with different types of verbs and the semantic distinctions they make. In particular, in Source-oriented events, German speakers often combine Path satellites with Path verbs, and in Goal-oriented events, they more frequently combine Path satellites with Manner verbs. In contrast, Polish speakers rely only on satellites to convey the Path which they use with Manner verbs in the description of both Source- and Goal-oriented events.

Finally, while in both languages the main semantic distinction conveyed by Path satellites is the presence or absence of boundary crossing for both Source and Goal, German speakers often combine Path satellites with deictic satellites, which they use more often in Source-oriented events. It appears therefore that spatial information in Source-oriented events in German is often distributed in two morphosyntactic loci - either in a Path satellite and a Path verb or in a Path satellite and a deictic satellite - and is, thus, expressed in a more fine-grained fashion than in Goaloriented events. 


\section{Source-Goal (a)symmetry in Ground expression}

In this section, we address the issue of the expression of the Ground, which is the reference location with respect to which the Path followed by the Figure is oriented. As we have seen earlier, in both German and Polish, such reference locations are typically introduced by prepositions and marked by case. In order to compare the expression of Grounds in the two languages, we first investigate the proportion of Grounds in the encoding of simple Path events - Source-oriented vs. Goaloriented -, then examine the choices German and Polish speakers make to describe complex Path events - Source-(Medial)-Goal -, and the types of Grounds they explicitly encode in their descriptions. Our main aim here is to assess to which reference location, Source or Goal, speakers of these two languages pay more attention in their descriptions and whether there is an asymmetry in the frequency of encoding of these elements and in the semantic granularity of their expression.

\subsection{Grounds in Source-oriented vs. Goal-oriented events}

The first observation regarding the expression of Grounds in simple Path events is that they are overwhelmingly present in both datasets, as illustrated in Table 14, with no significant difference between the two languages (not statistically significant difference: $\left.\chi^{2}=.29, d f=1, p>0.1^{\mathrm{ns}}\right) .{ }^{20}$

Table 14. The encoding of Grounds in German and Polish.

\begin{tabular}{lcccccc}
\hline Language & \multicolumn{2}{c}{ + Ground } & \multicolumn{2}{c}{ - Ground } & \multicolumn{2}{c}{ Total } \\
\hline German & $96 \%$ & $(292)$ & $4 \%$ & $(12)$ & $100 \%$ & $(304)$ \\
Polish & $95 \%$ & $(213)$ & $5 \%$ & $(11)$ & $100 \%$ & $(224)$
\end{tabular}

\footnotetext{
${ }^{20}$ A previous study of the expression of caused motion events (as opposed to spontaneous motion events) in Polish has revealed a more frequent omission of the Ground, accounting for $13.2 \%$ of the analyzed descriptions. The study showed a slight tendency to omit the Ground more frequently (1) in descriptions of removal (motion away from a location) than in placement events (motion toward a location), and (2) in descriptions of (un)clothing scenario than in other types of caused motion events (cf. Kopecka 2012).
} 
The following examples relating the same motion event illustrate the overt expression (26) and the omission (27) of the Ground (a tree) with respect to which the Figure (a girl) moves.

kobieta

pod-chodzi

do drzewa

woman.NOM.F.SG

up-walk.PRES.3SG to

tree.GEN.F.SG

'The girl walks out of the cave.' \{traj061_pol5\}

(27)

\section{Pod-chodzi}

up-walk.PRES.3SG

'(She) walks up.' \{traj061_pol9\}

If we now take a closer look at the expression of Source-oriented vs. Goal-oriented events, there is only little difference between the two event types in both German (Table 15) and Polish (Table 16), and, here again, not statistically significant $\left(\chi^{2}=3.1, d f=1, p>.05^{\text {ns }}\right.$ in German; $\chi^{2}=2.4$, $d f=1, p>.05^{\mathrm{ns}}$ in Polish).

Table 15. Grounds in Source- vs. Goal-oriented events in German.

\begin{tabular}{lllllll} 
Scene types & \multicolumn{2}{c}{ + Ground } & \multicolumn{2}{c}{ - Ground } & \multicolumn{2}{c}{ Total } \\
\hline Source-oriented & $94.1 \%$ & $(143)$ & $5.9 \%$ & $(9)$ & $100 \%$ & $(152)$ \\
Goal-oriented & $98.0 \%$ & $(149)$ & $2.0 \%$ & $(3)$ & $100 \%$ & $(152)$
\end{tabular}

Table 16. Grounds in Source- vs. Goal-oriented events in Polish.

\begin{tabular}{lcccccc}
\hline Scene types & \multicolumn{2}{c}{ + Ground } & \multicolumn{2}{c}{ - Ground } & \multicolumn{2}{c}{ Total } \\
\hline Source-oriented & $92.9 \%$ & $(104)$ & $7.1 \%$ & $(8)$ & $100 \%$ & $(112)$ \\
Goal-oriented & $97.3 \%$ & $(109)$ & $3.0 \%$ & $(3)$ & $100 \%$ & $(112)$
\end{tabular}

We may note that, regardless of the event type, the Ground tends to be omitted more often when the event does not imply boundary-crossing such as, for instance, walking away from an initial location and walking to(ward) a final location (compare (28) and (29) below). This observation is 
reminiscent of the results obtained in some languages in the study of caused motion events: speakers tend to omit the Ground more frequently in contexts which do not imply boundary crossing (e.g. 'take a cup off of a table') than in those which do involve it (e.g. 'take an orange out of a box'), see e.g. Ishibashi (2012) for Japanese (see also Nikitina 2008 for the study of in and into in English, showing that Goals implying boundary-crossing reveal different encoding preferences from Goals that do not imply boundary-crossing).

(28) eine Frau geht $\quad$ aus der Höhle heraus
a.NOM.F.SG woman go.PRS.3SG out a.DAT.F.SG cave hither.out
'A woman walks out of a cave'\{traj025_ger19\}
(29) vorhin ist er gekommen jetzt geht er wieder
before be.PRS.3SG he come.PST.PTCPnow go.PRS.3SG he again
'He came [toward the girl] earlier and now he goes away' $\{$ traj035_ger01\}

So far, we have looked at the expression of Grounds in the two event types without considering what type of reference location, Source, Medial or Goal, speakers encode when describing such events. Taking into account both the scene type and the Ground type, Tables 17 and 18 below show how speakers represent Grounds linguistically. Predictably, when depicting Source-oriented motion, speakers lay emphasis on the initial Ground and express it as a Source, and when depicting Goal-oriented motion they lay emphasis on the final Ground and express it as a Goal. However, beyond this main tendency, there are contexts that incite some speakers to pay attention to a different reference location than the one on which the emphasis is laid in the video. As reported in Table 17 below, the main phenomenon we observe is that German speakers sometimes tend to pay attention to the intermediary reference location and to encode it as either a Medial Ground or a Location. In the Polish dataset, as shown in Table 18, such choices are much 
less frequent. The difference between the two languages is statistically significant, with Grounds being expressed as Medial or Location more frequently in German than in Polish $\left(\chi^{2}=10.4, d f=1\right.$, $\left.p<.01^{* *}\right)$; this is the case for both Source-oriented events $\left(\chi^{2}=6.2, d f=1, p<.05^{*}\right)$ and Goaloriented events $\left(\chi^{2}=6.8, d f=1, p<.01^{* *}\right)$. Note that, at the intra-linguistic level, there is no statistically significant difference between the two event types, in either German $\left(\chi^{2}=.05, d f=1\right.$, $\left.p>.05^{\mathrm{ns}}\right)$ or Polish $\left(\chi^{2}=.02, d f=1, p>.05^{\mathrm{ns}}\right)$.

Table 17. Types of Grounds in the expression of Source- and Goal-oriented events in German.

\begin{tabular}{lclllllll}
\hline Scene types & \multicolumn{2}{c}{ Source } & \multicolumn{2}{c}{ Goal } & \multicolumn{2}{c}{ Medial or Location } & \multicolumn{2}{c}{ Total } \\
\hline Source-oriented & $82.5 \%$ & $(118)$ & $1.4 \%$ & $(2)$ & $16.1 \%$ & $(23)$ & $100 \%$ & $(143)$ \\
Goal-oriented & \multicolumn{2}{c}{} & $83.2 \%$ & $(124)$ & $16.8 \%$ & $(25)$ & $100 \%$ & $(149)$
\end{tabular}

Table 18. Types of Grounds in the expression of Source- and Goal-oriented events in Polish.

\begin{tabular}{lllllllll}
\hline Scene types & \multicolumn{2}{c}{ Source } & \multicolumn{2}{c}{ Goal } & \multicolumn{2}{c}{ Medial or Location } & \multicolumn{2}{c}{ Total } \\
\hline Source-oriented & $87.5 \%$ & $(91)$ & $6.7 \%$ & $(7)$ & $5.8 \%$ & $(6)$ & $100 \%$ & $(104)$ \\
Goal-oriented & $2.9 \%$ & $(3)$ & $91.3 \%$ & $(94)$ & $5.8 \%$ & $(6)$ & $100 \%$ & $(103)$
\end{tabular}

Finally, it should be pointed out that the Source in Source-oriented events and the Goal in Goaloriented events can be expressed alone (dominant pattern), or in combination with other Grounds (e.g. Source + Medial; Medial + Goal; Source + Goal). However, such expressions are not numerous in the data.

With regard to the prepositions used to introduce the Ground in German, we found 15 adpositional constructions, as well as nominal expressions. As shown in Table 19, among these constructions, 14 were used in the expression of the Ground in Goal-oriented events and 11 in the expression of the Ground in Source-oriented events. Some of them were used in the expression of both event types, albeit generally with highly different frequencies. Note that we coded as distinct 
constructions adpositions which can head NPs with different case marking, e.g. in + ACC 'into' vs. in + DAT 'in'.

Table 19. Prepositions found in simple Path events in German.

\begin{tabular}{lcc}
\hline & $\begin{array}{c}\text { Source-oriented events } \\
(\mathrm{N}=147 / 152)\end{array}$ & $\begin{array}{c}\text { Goal-oriented events } \\
(\mathrm{N}=151 / 152)\end{array}$ \\
\hline aus $_{\mathrm{DAT}}$ 'out of' & $\mathbf{9 7}$ & 1 \\
von $_{\mathrm{DAT}}$ 'from' & $\mathbf{2 5}$ & 14 \\
in $_{\mathrm{ACC}}$ 'into' & 6 & $\mathbf{7 9}$ \\
auf $_{\mathrm{ACC}} \ldots$ zu 'toward' & & $\mathbf{3 2}$ \\
$\mathrm{NP}$ & 31 & 12 \\
in $_{\mathrm{DAT}}$ 'in' & & 14 \\
über & & 14 \\
aufC 'over' & 8 & 3 \\
auf $_{\mathrm{DAT}}$ 'on, over' & 6 & 1 \\
auf $_{\mathrm{ACC}}$ 'toward' & 7 & 7 \\
durch $_{\mathrm{ACC}}$ 'through' & 2 & 12 \\
zu $_{\mathrm{DAT}}$ 'to' & 1 & 4 \\
zwischen $_{\mathrm{DAT}}$ 'between' & 3 & 3 \\
entlang $_{\mathrm{ACC}}$ 'along' (postposition) & 1 & 1 \\
an $_{\mathrm{ACC}} .$. entlang 'along' & & 1 \\
hinter $_{\mathrm{DAT}}$ 'behind' & & \\
in Richtung $_{\mathrm{GEN}}$ 'in the direction of & 1 &
\end{tabular}

The most frequent constructions in Goal-oriented events are the preposition in $_{\mathrm{ACC}}$ 'into' (79

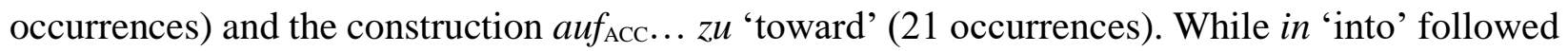
by the accusative indicates a boundary crossing (30), much like English into, the construction $a u f_{\mathrm{ACC}} \ldots z u$ 'toward' is used to describe motion toward a location (31).

(30) ein Junge rennt in das Meer

a.NOM.M.SG boy.NOM run.PRS.3SG in DET.ACC.N.SG sea

'A boy runs into the sea.' (traj059_ger12)

(31)

eine $\quad$ graut auf einen Baum zu

a.NOM.F.SG woman.NOM.SG go.PRS.3SG at a.ACC.M.SG tree toward

'A woman goes toward a tree.' (traj061_ger19) 
A third preposition, $z u_{\mathrm{DAT}}$ 'to, toward', is relatively frequent in descriptions of Goal-oriented events (12 occurrences). Its meaning is similar to that of the construction $a u f_{\text {ACC }} \ldots z u$, as illustrated in (31); however, in our data, $z u$ seems compatible both with situations in which there is a boundary crossing and with situations in which there is none; in this respect, it appears to be underspecified. In Source-oriented events, the most frequent prepositions are $a u s_{\text {DAT }}$ 'out of' (97 occurrences) and von $_{\mathrm{DAT}}$ 'from' (25 occurrences), with the same opposition: aus implies a boundary crossing, as is in (32), while von does not, as in (33).
(32) ein
Mann kommt
aus dem
Wald
a.NOM.M.SG man come.PRS.3SG out.of the.DAT.M.SG forest
'A man comes out of the forest.' (traj055_ger19)
(33) eine
Frau die sich vom
a.NOM.F.SG woman walk.PRS.3SG oneself from.the.DAT.M.SG tree entfernt
Baum
distance.PRS.3SG
'A woman who goes away from the tree.' (traj032_ger18)

These observations suggest that, in German, there is a difference in the use of adpositional constructions for descriptions of Source-oriented vs. Goal-oriented motion. In descriptions of Source-oriented motion, we found a binary opposition ([+ boundary-crossing], [- boundarycrossing]). The semantic distinctions found in descriptions of Goal-oriented motion are slightly more complex, with a similar binary opposition, and a third construction which seems to be underspecified ([+ boundary-crossing], [- boundary-crossing $],([ \pm$ boundary-crossing $])$.

In Polish, we found 14 prepositions, in addition to nominal and adverbial expressions that were occasionally used. As Table 20 shows, among these prepositions, 10 were used in the 
expression of Grounds in Goal-oriented events and 8 in the expression of Grounds in Sourceoriented events, some of them being used, with varying frequencies, in both event types.

Table 20. Prepositions found in simple Path events in Polish.

\begin{tabular}{lcc}
\hline & $\begin{array}{c}\text { Source-oriented events } \\
(\mathrm{N}=103 / 112)\end{array}$ & $\begin{array}{c}\text { Goal-oriented events } \\
(\mathrm{N}=106 / 112)\end{array}$ \\
\hline$d o$ 'to' + GEN & 3 & $\mathbf{6 4}$ \\
w'in' + ACC & $\mathbf{7 1}$ & $\mathbf{2 2}$ \\
$z$ 'from' + GEN & $\mathbf{1 5}$ & 1 \\
od 'off' + GEN & 3 & 1 \\
NP & 3 & 6 \\
przez 'across, through' + ACC & & 5 \\
w 'in' + LOC & & 2 \\
ADV & & 1 \\
między 'between' + ACC & & 1 \\
na 'on' + ACC & & 1 \\
pod 'under' + ACC & 5 & 1 \\
pod 'under' + INSTR & 1 & 1 \\
w strone 'in the direction' + GEN & 1 & \\
spod 'from.under' + GEN & 1 & \\
spomiędzy 'from.between' + GEN & & \\
spośród 'from.among' + GEN & &
\end{tabular}

If we now look at the prepositions showing the highest number of occurrences, in Goal-oriented events, the most frequent are $d o$ 'to' + GEN (64 occurrences) and $w$ 'in' + ACC (22 occurrences). Of the two, $w$ 'in' is semantically more specific in that it indicates direction toward an enclosed, and often dense, Ground, a configuration which do 'to' is not sensitive to, as the examples (34) and (35) illustrate.

$\begin{array}{llll}\text { chtopiec } & \text { w-biega } & \text { do } & \text { morza } \\ \text { boy.NOM.M.SG } & \text { in-run.PRS.3SG } & \text { to } & \text { sea.GEN.N.SG }\end{array}$

'The boy is running into the sea.' (traj059_pol02)

(35) kobieta

$$
\text { we-szła } \quad w \text { pole kukurydzy }
$$

woman.NOM.F.SG in-walk.PST.F.3SG in field.ACC.N.SG corn.GEN.F.SG

'The woman went into the corn field.' (traj069_pol03) 
In Source-oriented events, the most frequent prepositions are $z$ 'from' + GEN (71 occurrences) and $o d$ 'off' + GEN (15 occurrences). The latter is semantically more specific in that it indicates the separation from the Ground with which the Figure was in (loose or tight) contact and which is thus conceived as a point in space, as in (37); the preposition $z$ 'from', as in (36), is not sensitive to this parameter, and can be used in a greater variety of contexts.

kobieta

wy-chodzi

$z$

pola

kukurydzy

woman.NOM.F.SG

in-walk.PRS.3SG from

field.GEN.N.SG

corn.GEN.F.SG

'The woman is walking out of the corn field with the basket.' (traj038_pol05)

(37)

$\begin{array}{llll}\text { kobieta } & \text { od-chodzi } & \text { od } & \text { drzewa } \\ \text { woman.NOM.F.SG } & \text { off-walk.PRS.3SG } & \text { off } & \text { tree.GEN.N.SG }\end{array}$

'The woman is walking away from the tree.' (traj032_pol07)

Based on the data presented in Tables 19 and 20, we can observe some differences between the two languages. In German, participants show a slight tendency for differentiating the Goal more often than the Source, with several frequent prepositions introducing the Goal, and only one highly frequent preposition for the Source.

In Polish, the difference between prepositions used for Source and Goal expression lies merely in the type of semantic distinctions they lexicalize, rather than in their frequency and semantic granularity. In particular, each pair of prepositions contains one item which lexicalizes the configuration of the Ground and one that is underspecified: [ \pm density] for the Goal and $[ \pm$ contact] for the Source. 


\subsection{Grounds in complex Path events}

The question we would like to explore now is how German and Polish speakers represent the Ground in complex Path events (i.e. motion in relation to two or three reference locations), and to which type of Ground, Source, Goal or Medial, they allocate more attention when depicting such events. To address this issue, we examine the descriptions of $(i)$ two scenes in which the protagonist moves from a source location to a goal location: one scene implies a boundary crossing at the endpoint (from cliff into sea) while the other does not (from one rock to another), and (ii) one scene in which the protagonist moves from a Source location via a Medial location to a Goal location (out of cave - past basket - into cave).

Let us first look at the expression of Source-Goal events. As Table 21 below shows, while in both languages some speakers do encode one Ground only, the majority of them encode both the Source and the Goal Ground in their descriptions. This concerns $81.6 \%$ of motion descriptions in German and $71.4 \%$ in Polish (not a statistically significant difference: $\chi^{2}=.03, d f=1, p>.05^{\mathrm{ns}}$ ).

Table 21. Grounds in Source-Goal events in German and Polish.

\begin{tabular}{|c|c|c|c|c|c|}
\hline Language & No Ground & 1 Ground & $2 \mathbf{G}$ & inds & Total \\
\hline German & - & $18.4 \%$ & $81.6 \%$ & (31) & $100 \%$ \\
\hline Polish & $3.6 \%$ & $25 \%$ & $71.4 \%$ & (20) & $100 \%$ \\
\hline
\end{tabular}

If we now look in more detail at the two events considered here, the results presented in Tables 22 and 23 below show some subtle differences between the two languages: German speakers tend to express Source and Goal Grounds more frequently in the description of the scene 1 (a boy jumps from the cliff into the sea), while Polish speakers do so more frequently in the description of the scene 2 (a boy jumps from one rock to another). Speakers of both languages tend to describe these events in an iconic way, following the temporal unrolling of the event from Source to Goal. Interestingly, however, there is a difference in the encoding of the two scenes in Polish. The scene 
1 prompted a more frequent choice of a non-iconic perspective with Goal being expressed prior to Source compared to the scene 2 . The choice of this perspective may be motivated by the distance between the two reference locations (cliff and sea) and the attention paid to the boundary crossing, i.e. the protagonist's plunging into the sea at the endpoint of the event. As a matter of fact, we do not observe this particular perspective in the description of a short distance motion where the protagonist jumps from one rock to another and where he does not cross any boundary. A further argument for the salience of the endpoint in the diving scene is the fact that when speakers choose to encode one reference location only, they typically choose the Goal, at least in Polish, albeit the encoding of one Ground only is infrequent (4 out of 14 descriptions).

Table 22. Grounds in the expression of Source-Goal events in German.

\begin{tabular}{|c|c|c|c|c|}
\hline \multirow{2}{*}{$\begin{array}{l}\text { Grounds } \\
\text { Source + Goal }\end{array}$} & \multicolumn{2}{|c|}{$\begin{array}{c}\text { SCENE } 1 \\
\text { A boy jumps from the } \\
\text { cliff into the sea }\end{array}$} & \multicolumn{2}{|c|}{$\begin{array}{c}\text { SCENE } 2 \\
\text { A boy jumps from one } \\
\text { rock to another rock }\end{array}$} \\
\hline & $89 \%$ & (17) & $74 \%$ & (14) \\
\hline Goal & $11 \%$ & (2) & $21 \%$ & (4) \\
\hline Source & \multicolumn{2}{|c|}{-} & $5 \%$ & (1) \\
\hline Total & $100 \%$ & (19) & $100 \%$ & (19) \\
\hline
\end{tabular}

Table 23. Grounds in the expression of Source-Goal events in Polish.

\begin{tabular}{|c|c|c|c|c|}
\hline \multirow{2}{*}{$\begin{array}{l}\text { Grounds } \\
\text { Source + Goal }\end{array}$} & \multicolumn{2}{|c|}{$\begin{array}{c}\text { SCENE } 1 \\
\text { A boy jumps from the } \\
\text { cliff into the water }\end{array}$} & \multicolumn{2}{|c|}{$\begin{array}{c}\text { SCENE } 2 \\
\text { A boy jumps from one } \\
\text { rock to another rock }\end{array}$} \\
\hline & $64.3 \%$ & (9) & $78.6 \%$ & (11) \\
\hline Source + Goal & $42.9 \%$ & (6) & $78.6 \%$ & (11) \\
\hline Goal + Source & $21.4 \%$ & (3) & - & \\
\hline Goal & $28.6 \%$ & (4) & & \\
\hline Medial & \multicolumn{2}{|c|}{-} & $21.4 \%$ & (3) \\
\hline No Ground & $7.1 \%$ & (1) & \multicolumn{2}{|c|}{-} \\
\hline Total & $100 \%$ & (14) & $100 \%$ & (14) \\
\hline
\end{tabular}


As regards the description of motion from an initial location (walking out of the cave) via medial location (passing nearby a basket) to a final location (walking into another cave), we observe more variation between German and Polish speakers in their attention to the type of Grounds they encode. In German (Table 24), speakers tend to encode more than one Ground, and a majority of speakers actually explicitly express all three reference locations. The order in which these elements are arranged in the sentence may vary from speaker to speaker, the iconic order Source-MedialGoal being the most frequent.

Table 24. Grounds in the expression of Source-Medial-Goal events in German.

\begin{tabular}{llll}
\hline Grounds & Types of Grounds & \multicolumn{2}{c}{$\mathbf{N = 1 9}$} \\
\hline \multirow{2}{*}{ Ground $(\mathrm{N}=1)$} & Medial & $5 \%$ & $(1)$ \\
& Medial + Goal & $11 \%$ & $(2)$ \\
2 Grounds $(\mathrm{N}=4)$ & Goal + Medial & $5 \%$ & $(1)$ \\
& Medial + Source & $5 \%$ & $(1)$ \\
& Source + Medial + Goal & $42 \%$ & $(8)$ \\
3 Grounds $(\mathrm{N}=14)$ & Medial + Source + Goal & $16 \%$ & $(3)$ \\
& Source + Goal + Medial & $16 \%$ & $(3)$
\end{tabular}

In Polish, there is more variation among speakers in this respect. As we can see in Table 25, in contrast to German, the encoding of the three Grounds is infrequent in the descriptions of this event in the Polish data: three speakers only encoded Source, Medial and Goal; the other speakers encoded either one Ground (mainly the Medial) or two Grounds (either Median and Goal or Source and Goal). 
Table 25. Grounds in the expression of Source-Median-Goal events in Polish.

\begin{tabular}{llll}
\hline Grounds & Types of Grounds & \multicolumn{2}{c}{$\mathbf{N = 1 4}$} \\
\hline \multirow{3}{*}{1 Ground $(\mathrm{N}=7)$} & Medial & $35.7 \%$ & $(5)$ \\
& Goal & $7.1 \%$ & $(1)$ \\
& Source & $7.1 \%$ & $(1)$ \\
& Medial + Goal & $14.3 \%$ & $(2)$ \\
\multirow{2}{*}{ Grounds $(\mathrm{N}=4)$} & Goal + Medial & $7.1 \%$ & $(1)$ \\
& Source + Goal & $7.1 \%$ & $(1)$ \\
& Source + Goal + Medial & $14.3 \%$ & $(2)$ \\
& Source + Medial + Goal & $7.1 \%$ & $(1)$
\end{tabular}

Table 26 shows the prepositions used in the descriptions of complex Path events in German. Two prepositions were found for the expression of the Source, von + DAT 'from' and aus + DAT 'out of', though only the former appeared with a high frequency (in more than half of the descriptions). Four prepositions were found for the expression of the Goal, in + ACC 'into', auf + ACC 'toward', $z u+$ DAT 'to, toward' and in + DAT 'in'. The description of the Goal with prepositions was thus both more frequent and more detailed than that of the Source in complex Path descriptions. Only two prepositions were found for the expression of Medial Grounds, an + DAT 'by' and um + DAT 'around' (associated with rum 'around'). Source Grounds and Medial Grounds were often expressed as NPs with no preposition, a construction also found for Goals, as illustrated in (38), albeit less frequently.

Table 26. Diversity of prepositions in complex Path events in German.

\begin{tabular}{lll}
\hline SOURCE & MEDIAL & GOAL \\
\hline von + dat 'from' (27 occ.) & an + dat 'by' $(8$ occ. $)$ & in + acc 'into' $(31$ occ. $)$ \\
aus + dat 'out of' (6 occ.) & $u m+$ dat 'around' + rum (1 occ.) & auf + acc 'toward' $(10$ occ. $)$ \\
NPs (14 occ.) & NPs (10 occ.) & $z u+$ dat 'to, toward' $(9$ occ. $)$ \\
& & NPs $(3$ occ.) \\
& in + dat 'in' $(2$ occ. $)$
\end{tabular}


(38)

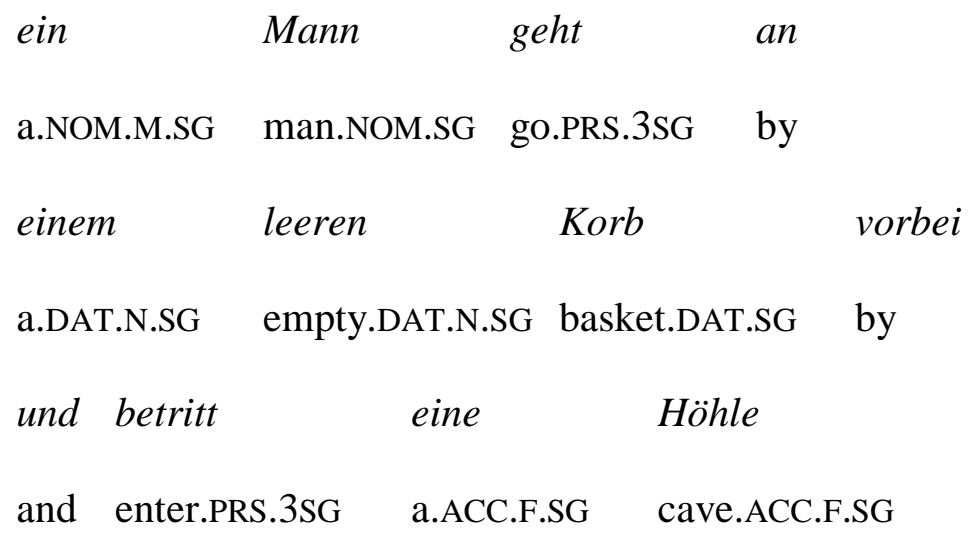

'A man goes by an empty basket and enters a cave'. \{traj060_ger11\}

Table 27 shows the variety of prepositional expressions, in addition to one nominal expression, found in the descriptions of complex Path events in Polish. Interestingly, the Medial Ground triggered the greatest diversity of prepositions. As regards the expression of Source and Goal, which are of interest in this study, one preposition, $z$ 'from' + GEN, was used for the expression of the Source and two, do 'to' + GEN and $n a$ 'on' + ACC, in the expression of the Goal. This difference is mostly due to the types of Goal Grounds displayed in the video-clips. As a matter of fact, two types of Grounds, the sea into which the Figure plunges and the rock upon which the Figure jumps, play the role of final locations contrasted with one type of Ground, an open surface (cliff and rock) that plays the role of the initial location.

Table 27. Diversity of prepositions in complex Path events in Polish.

\begin{tabular}{|c|c|c|}
\hline SOURCE & MEDIAL & GOAL \\
\hline$z$ 'from' + gen (24 occ.) & $\begin{array}{l}\text { obok 'at the side'+ gen (6 occ.) } \\
\text { po 'on, along' + loc (3 occ.) } \\
\text { koto 'around' + gen (2 occ. }) \\
\mathrm{NP}_{\text {instr }}(3 \text { occ. })\end{array}$ & $\begin{array}{l}d o \text { 'to' }+ \text { gen }(20 \text { occ. }) \\
n a \text { 'on' }+ \text { acc (11 occ.) }\end{array}$ \\
\hline
\end{tabular}




\subsection{Summary: Source-Goal asymmetry in Ground expression}

As evidenced by the explicit encoding of Source and Goal Grounds, the data discussed in this section do not show a straightforward asymmetry in the expression of the two elements in German and Polish. More specifically, in simple Path events, the frequency of Source and Goal encoding is very high in both languages, revealing that speakers may pay attention to both types of Ground (cf. Tables 17 and 18). In complex Path events, there is more variation both across event types and across languages. Namely, in Source-Goal events (a boy jumps from cliff into water, a boy jumps from one rock onto another), speakers tend to encode both Source and Goal, in both languages. (cf. Tables 22 and 23). In Source-Medial-Goal events, however, the difference between the two languages in the type of Ground elements the participants select for the linguistic expressions is more noticeable. German speakers frequently encode Source and Goal, in addition to Medial, whereas Polish speakers, in most cases, express only one Ground, preferentially the Medial, or two Grounds, preferentially Medial and Goal; Source is less frequently encoded in their descriptions, revealing thereby a slight bias toward the Goal (cf. Tables 24 and 25). Finally, concerning the use of prepositional phrases which introduce the Ground, while the diversity of prepositions found in Source and Goal expressions is limited in both languages, there is some variation in their frequency of use. When encoding Goals, German speakers resort to different prepositions more frequently, thereby making finer semantic distinctions in comparison with the encoding of the Source. In Polish, by contrast, there is little variation in the frequency of use of prepositions introducing Source and Goal. 


\section{Conclusion}

In this paper, we analyzed descriptions of motion events in German and Polish, depicting both simple Path events with a focus on the initial location (Source) or the final location (Goal), and complex Path events with a focus on both the initial and the final location - in addition to an intermediary location (Medial). We showed that German and Polish speakers rely on a similar set of linguistic items to describe the different Path components: satellites (verb particles and prefixes in German and verb prefixes in Polish), verbs, case marking and prepositional phrases. However, the data also showed that there are differences across the two languages in terms of diversity of these resources (types) and their frequency of use in motion descriptions (tokens). Among these differences is the fact that, in Polish, Path verbs display a much lower frequency that in German, and, more notably, that verb satellites appear to be more grammaticalized than in German (higher frequency, smaller set of forms). Another notable difference is the use of deictic forms in German, including both verbs (kommen 'to come' and gehen 'to go') and satellites (simple verb prefixes, mainly hin- 'thither' and her- 'hither', and compound verb particles such as hinaus 'thither.out' and herein 'hither.in').

Importantly, the data discussed in this study shed light on the phenomenon of Source/Goal asymmetry, and on cross-linguistic differences in the degree of this asymmetry. First, as regards the expression of the Path of motion, there are cross-linguistic differences in the types of constructions used by speakers to describe Source-oriented vs. Goal-oriented events. In German, we found a significantly stronger tendency for speakers to convey Path in both verb prefix and verb root in Source-oriented events as compared to Goal-oriented events. Furthermore, the German data reveal a difference in the expression of deictic Path, which is significantly more frequent in Source-oriented events. When describing such events, German speakers frequently use the verb 
kommen 'to come', thereby revealing an asymmetry in deictic anchoring in favor of Sourceoriented events. In Polish, by contrast, the data show a consistent symmetry across event types, both structurally and in terms of frequency. Moreover, they reveal no deictic perspective in motion descriptions by Polish speakers, neither in Source-oriented nor in Goal-oriented events. Second, as regards the expression of the Ground, the asymmetry between Source and Goal is not straightforward. The expression of Source Grounds and Goal Grounds is rarely omitted in motion descriptions by German and Polish speakers, and their high frequency of expression suggests that, when depicting a change of location, speakers pay attention to both Source and Goal. However, here again, the data reveal subtle cross-linguistic differences in the diversity of prepositions (PREP + CASE). German speakers resort to different prepositions more frequently in Goal expression as compared to Source expression. Polish data, however, show little variation in the diversity and frequency of prepositions used to introduce Source and Goal.

To conclude, it has often been postulated that the asymmetry between Source and Goal is wide-spread and merely motivated by cognitive and pragmatic factors. However, the results of our study suggest that the phenomenon of Source/Goal asymmetry is both complex and elusive, and that it can take different forms and display different degrees depending on language-specific characteristics. One of the interesting outcomes of the data investigated in this study concerns the asymmetry observed in German in the structural complexity of Path and the expression of the deictic perspective, which contrasts with the structural and semantic symmetry observed in Polish. Further research should establish whether these tendencies can be corroborated on larger corpora and pragmatically contextualized datasets, including a greater diversity of event types.

\section{Abbreviations}
$1,2,3$
$1^{\text {st }}, 2^{\text {nd }}, 3^{\text {rd }}$ person
INSTR
INSTRUMENTAL 


$\begin{array}{llll}\text { PTCP } & \text { participle } & \text { M } & \text { masculine } \\ \text { PREP } & \text { preposition } & \text { N } & \text { neuter } \\ \text { ACC } & \text { accusative } & \text { NOM } & \text { nominative } \\ \text { ADV } & \text { adverb } & \text { PL } & \text { plural } \\ \text { DAT } & \text { dative } & \text { PRS } & \text { present } \\ \text { DET } & \text { determiner } & \text { PST } & \text { past } \\ \text { F } & \text { feminine } & \text { REFL } & \text { reflexive } \\ \text { GEN } & \text { genitive } & \text { SG } & \text { singular } \\ \text { LOC } & \text { locative } & & \end{array}$

\section{References}

\section{MISSING REFERENCES:}

Kopecka \& Ishibashi 2011

Kopecka \& Vuillermet, this vol.

Lehmann 2002

Stefanowitsch 2018

Wunderlich 1983

Aurnague, Michel. 2011. 'Quittant tout, nous partîmes': 'quitter' et 'partir' à la lumière des changements de relation locative. Journal of French Language Studies 21(3). 285-312.

Behrens, Heike. 2010. Direction and Perspective in German Child Language. In Jiansheng Guo, Elena Lieven, Nancy Budwig, Susan Ervin-Tripp, Keiko Nakamura \& Seyda Ozcaliskan (eds.), Crosslinguistic approaches to the psychology of language: Research in the tradition of Dan Isaac Slobin, 55-67. Psychology Press. 
52 Benjamin Fagard \& Anetta Kopecka

Berthele, Raphael. 2013. Disentangling manner and path Evidence from varieties of German and Romance. In Juliana Goschler and Anatol Stefanowitsch (eds.), Variation and Change in the Encoding of Motion Events, 55-76. [VV: not cited in text]

Bohnemeyer, Jürgen, Nicholas J. Enfield, James Essegbey, Iraide Ibarretxe-Antuñano, Sotaro Kita, Friederike Lüpke \& Felix K., Ameka. 2007. Principles of event segmentation in language: The case of motion events. Language 83(3), 495-532.

Bourdin, Philippe. 1997. On goal-bias across languages: modal, configurational and orientational parameters. Proceedings of LP '96: Typology: prototypes, item orderings and universals, proceedings of the conference held in Prague, August 20-22, 1996. 185-216.

De Knop, Sabine and Françoise Gallez. 2013. Manner of motion: A privileged dimension of German expressions. In Thomas Li (ed.), Compendium of cognitive linguistics research, 25-42. Hauppage, NY: Nova Science Publishers.

Dewell, Robert B. 2011. The meaning of particle/prefix constructions in German. Amsterdam/Philadelphia: John Benjamins.

Dewell, Robert B. 2015. The semantics of German verb prefixes. Amsterdam/Philadelphia: John Benjamins.

Dirven, René \& Marjolijn Verspoor (eds.). 1998. Cognitive exploration of language and linguistics. Amsterdam/Philadelphia: John Benjamins.

Engelen, Bernhard. 1995. Hinunter versus darunter. Beobachtungen und Überlegungen zu den Direktionaladverbien. In Ludwig M. Eichinger \& Hans-Werner Eroms (eds.), Dependenz und Valenz, 243-258. Hamburg: Buske.

Fagard, Benjamin, Jordan Zlatev, Anetta Kopecka, Masimo Cerruti \& Johan Blomberg. 2013. The expression of motion events: A quantitative study of six typologically varied 
languages. Proceedings of the 39th Annual Meeting of the Berkeley Linguistics Society, Berkeley, 364-379.

Georgakopoulos, Thanasis. 2018. A frame-based approach to the source-goal asymmetry: Synchronic and diachronic evidence from Ancient Greek. Constructions and Frames 10(1). 61-97.

Ikegami, Yoshihiko. 1987. 'Source’ vs. 'Goal': A case of linguistic dissymmetry. In René Dirven \& Günter Radden (eds), Concept of case, 122-146. Tübingen: Günter Narr Verlag. Imbert, Caroline, Colette Grinevald \& Anna Sörés. 2011. Pour une catégorie de "satellite" de Trajectoire dans une approche fonctionnelle-typologique. Faits de Langues - Les Cahiers 38(2). 99-116.

Ishibashi, Miyuki, Anetta Kopecka \& Marine Vuillermet. 2006. Trajectoire: Matériel visuel pour élicitation des données linguistiques. Laboratoire Dynamique du Langage (CNRS / Université Lyon 2) - Fédération de Recherche en Typologie et Universaux Linguistiques, CNRS, France.

Ishibashi, Miyuki. 2015. A field method to describe spontaneous motion events in Japanese. Proceedings of the Annual Meeting of the Berkeley Linguistics Society 41. 197-218. Jackendoff, Ray. 1983. Semantics and cognition. Cambridge, MA: MIT Press.

Kopecka, Anetta. 2010. Motion events in Polish: lexicalization patterns and semantic distribution of Manner. In Viktoria Hasko \& Renee Perellmuter (eds), Multiple perspectives on Slavic verbs of motion, 225-246. Amsterdam/Philadelphia: John Benjamins.

Kopecka, Anetta. 2012. Semantic granularity in the expression of placement and removal events in Polish. In Anetta Kopecka \& Bhuvana Narasimhan (eds), Events of putting and taking: A crosslinguistic perspective, 327-347. Amsterdam/Philadelphia: John Benjamins. 
54 Benjamin Fagard \& Anetta Kopecka

Kopecka, Anetta \& Miyuki Ishibashi. 2011. L'(a)symétrie dans 1'expression de la Source et du But : perspective translinguistique. Les Cahiers de Faits de Langues 3. 131-149.

Kopecka, Anetta \& Marine Vuillermet. This vol. Source-Goal (a)symmetry across languages: An introduction. Studies in Language XX.

Lakusta, Laura \& Barbara Landau. 2005. Starting at the end: the importance of goals in spatial language. Cognition 96. 1-33.

Lehman, Christian. 2002. Thoughts on Grammaticalization. Second revised edition. Arbeitspapiere des Seminars für Sprachwissenschaft der Universität Erfurt Nr. 9.

Lewandowski, Wojciech \& Jaume Mateu. 2016. Thinking for translating and intra-typological variation in satellite-framed languages. Review of Cognitive Linguistics 141(1). 185-208.

Lewandowski, Wojciech. 2014. The locative alternation in verb-framed vs. satellite-framed languages: A corpus study of Spanish and Polish. Studies in Language 38(4). 864-895.

Lewandowski, Wojciech. 2018. A typological approach of the encoding of motion events. In María de los Ángeles Gómez González \& J. Lachlan Mackenzie (eds), The construction of discourse as verbal interaction, 45-74. Amsterdam/Philadelphia: John Benjamins.

Los, Bettelou, Corrien Blom, Geert Booij, Marion Elenbaas \& Ans van Kemenenade. 2012. Morphosyntactic change: A comparative study of particles and prefixes. Cambridge: Cambridge University Press.

Łozińska, Joanna. 2018. Path and manner saliency in Polish in contrast with Russian: A cognitive linguistic study. Leiden: Brill.

Lüdeling, Anke. 2001. On particle verbs and similar constructions in German. Stanford: CSLI Publications. 
Narasimhan, Bhuvana, Anetta Kopecka, Melissa Bowerman, Marianne Gullberg \& Asifa Majid. 2012. Putting and taking events: A cross-linguistic perspective, In Kopecka, Anetta and Bhuvana Narasimhan (eds), Events of putting and taking, 1-18. Amsterdam/Philadelphia: John Benjamins.

Nikitina, Tatiana. 2008. Pragmatic factors and variation in the expression of spatial goals: The case of into vs. in. In Anna Asbury, Jakub Dotlačil, Berit Gehrke \& Rick Nouwen (eds), Syntax and semantics of spatial P, 175-195. Amsterdam/Philadelphia: John Benjamins.

Pfeifer, Wolfgang (dir.). 1993. Etymologisches Wörterbuch des Deutschen. $2^{\text {nd }}$ edn. Berlin: Akademie Verlag.

Regier, Thierry \& Mingyu Zheng. 2007. Attention to endpoints: A cross-linguistic constraint on spatial meaning. Cognitive Science 31. 705-719.

Slobin, Dan Isaac, Iraide Ibarretxe-Antuñano, Anetta Kopecka \& Majid Asifa. 2014. Manners of human gait: A crosslinguistic event-naming study. Cognitive Linguistics 25. 701-741.

Stefanowitsch, Anatol \& Ada Rodhe. 2004. The goal bias in the encoding of motion events. In Günter Radden \& Klaus-Uwe Panther (eds), Studies in linguistic motivation, 249-267. Berlin: Mouton de Gruyter.

Stefanowitsch, Anatol. 2018. The goal bias revised: A collostructional approach. Yearbook of the German Cognitive Linguistics Association 6(1). 143-166.

Stevens, Christopher M. 2011. Grammaticalization in spatial deixis: A case study. In Irmengard Rauch, Gerald F. Carr \& Robert L. Kyes (eds), On Germanic linguistics: Issues and methods, 299-313. Berlin/New York: Mouton de Gruyter.

Svorou, Soteria. 1994. The grammar of space. Amsterdam/Philadelphia: John Benjamins. 
Talmy, Leonard. 1985. Lexicalization patterns: semantic structure in lexical form. In Shopen, Timothy (ed.), Language typology and semantic description. Vol. 3: Grammatical categories and the lexicon, 36-149. Cambridge: Cambridge University Press.

Talmy, Leonard. 2000. Toward a cognitive semantics. Cambridge, MA: MIT Press.

Ungerer, Friedrich \& Hans-Jörg Schmid. 1996. An introduction to cognitive linguistics. London/New York: Longman.

Verkerk, Annemarie. 2017. The goal-over-source principle in European languages: Preliminary results from a parallel corpus study. In Silvia Luraghi, Tatiana Nikitina \& Chiara Zanchi (Eds), Space in diachrony, 1-40. Amsterdam/Philadelphia: John Benjamins.

Verspoør, Marjolijn, Dirven, René and Günter Radden. 1998. Putting concepts together: Syntax. In René Dirven and Marjolijn Verspe日r (Eds), Cognitive expleration of language and linguisties. Amsterdam/Philadelphia: John Benjamins, 79-105. [VV: not cited in text]

Vuillermet, Marine \& Anetta Kopecka. 2019. Trajectoire: a methodological tool for eliciting Path of motion. Methodological tools for linguistic description and typology. Special issue of Language, Documentation and Conservation 16. 97-124.

Wunderlich, Dieter. 1983. On the Compositionality of German Prefix Verbs. In Rainer Bäuerle, Christoph Schwarze \& Arnim von Stechow (Eds.), Meaning, Use, and Interpretation of Language. Berlin/New York: Walter de Gruyter, 452-465.

\section{Address for correspondence}

benjamin.fagard@ens.psl.eu 


\section{Co-author information}

$\underline{\text { Anetta.Kopecka@univ-lyon2.fr }}$ 